\title{
去氢枞酸硝酸酯类化合物的合成及细胞毒性评价
}

\author{
李芳耀 $a, b$ 黄 琳 ${ }^{b}$ 周小群 ${ }^{b}$ 李 倩 $b$ \\ 马献力 $b$ 段文贵*, $a$ 王 秀 $a$ \\ ( ${ }^{a}$ 广西大学化学化工学院 南宁 530004) \\ ${ }^{b}$ 桂林医学院药学院 广西桂林 541004)
}

\begin{abstract}
摘要 为寻找高效的抗肿瘤活性化合物, 设计并合成了一系列新型的去氢枞酸硝酸酯类化合物. 采用噻唑蓝(MTT)法 测定目标化合物对鼻咽癌(CNE-2)、肝癌(HepG2, BEL-7402)和宫颈癌(HeLa)细胞株以及人正常肝细胞株(HL-7702)和鼻 咽上皮细胞株(NP69)的细胞毒活性. 结果表明, 大多数杂合物的细胞毒性明显高于母体化合物. 其中, 12-溴去氢枞酸$3^{\prime}$-硝氧基丙酯(5j)对鼻咽癌 CNE-2 细胞株的抑制增殖活性优于顺铂, $\mathrm{IC}_{50}$ 值为 $(8.36 \pm 0.14) \mu \mathrm{mol} / \mathrm{L}, 12,14-$ 二硝基去氢枞 酸-3'-硝氧基丙酯(5n)对肝癌 BEL-7402 细胞株的 $\mathrm{IC}_{50}$ 值为(11.23 \pm 0.21$) \mu \mathrm{mol} / \mathrm{L}$. 同时，目标化合物对人正常肝细胞株 (HL-7702)和鼻咽上皮细胞株(NP69)表现出较低的细胞毒性. 此外, 对所有硝酸酯的 NO 释放量的测试表明, 在大多数 情况下, 细胞毒性与 CNE-2 细胞株细胞内 NO 的释放水平呈正相关.
\end{abstract}

关键词 去氢枞酸; 硝酸酯; 合成; 细胞毒性

\section{Synthesis and Cytotoxicity Evaluation of Dehydroabietic Acid Derivatives Bearing Nitrate Moiety}

\author{
Li, Fangyao ${ }^{a, b}$ Huang, $\operatorname{Lin}^{b} \quad$ Zhou, Xiaoqun $^{b} \quad$ Li, Qian ${ }^{b}$ \\ Ma, Xianli ${ }^{b}$ Duan, Wengui ${ }^{*, a} \quad$ Wang, Xiu ${ }^{a}$ \\ ( ${ }^{a}$ School of Chemistry and Chemical Engineering, Guangxi University, Nanning 530004) \\ ( ${ }^{b}$ School of Pharmacy, Guilin Medical University, Guilin, Guangxi 541004)
}

\begin{abstract}
In order to find more effective antitumor agents, a series of novel dehydroabietic acid derivatives bearing nitrate moiety were designed and synthesized. Their cytotoxicities were evaluated against human cancer cell lines of CNE-2 (nasopharynx), HepG2 (liver), HeLa (epithelial cervical) and BEL-7402 (liver), and human normal liver cell (HL-7702) and nasopharyngeal epithelial cell (NP69) using methyl thiazolyl tetrazolium (MTT) assay. Biological screening results demonstrated that most of the hybrids exhibited more potent cytotoxicity superior to parent compound dehydroabietic acid. Among them, 12-bromodehydroabietic acid-3'-nitrooxypropyl ester (5j) displayed better antiproliferative activity with $\mathrm{IC}_{50}$ value of $(8.36 \pm$ $0.14) \mu \mathrm{mol} / \mathrm{L}$ toward CNE-2 cells compared with cisplatin, and 2,14-dinitrodehydroabietic acid-3'-nitrooxypropyl ester (5n) showed remarkable cytotoxicity with $\mathrm{IC}_{50}$ value of $(11.23 \pm 0.21) \mu \mathrm{mol} / \mathrm{L}$ against BEL-7402 cells. Moreover, they exhibited lower cytotoxicity against human normal liver cell line HL-7702 and nasopharyngeal epithelial cell NP69. Besides, NO released amounts detection of all nitrates suggested that in most cases, the cytotoxicities were positively correlated with the levels of intracellular NO release in CNE-2 cells.
\end{abstract}

Keywords dehydroabietic acid; nitrate; synthesis; cytotoxicity

\footnotetext{
* Corresponding author. E-mail: wgduan@gxu.edu.cn

Received March 29, 2020; revised May 23, 2020; published online June 24, 2020.

Project supported by the Guangxi Natural Science Foundation of China (Nos. 2018GXNSFAA138165, 2018GXNSFAA281200), the State Key Laboratory for Chemistry and Molecular Engineering of Medicinal Resources (Guangxi Normal University) (No. CMEMR2019-B02), the Open Fund of Guangxi Key Laboratory of Chemistry and Engineering of Forest Products (No. GXFC18-02), the Open Fund of Guangxi Key Laboratory of Agricultural Resources Chemistry and Biotechnology (No. 2019KF06), the Cultivating Project of a Thousand of Young and Middle-Aged Key Teachers in Guangxi Colleges and Universities, the Youth Promotion Project Fund of Guangxi (No. 2019KY0551), and the Project to Improve the Basic Research Ability of Middle and Young Teachers in Guilin Medical University (No. 2018glmcy015).

广西自然科学基金(Nos. 2018GXNSFAA138165, 2018GXNSFAA281200)、省部共建药用资源化学与药物分子工程国家重点实验室资助课题(广西师范 大学)(No. CMEMR2019-B02)、广西林产化学与工程重点实验室开放基金课题(No. GXFC18-02)、广西农产资源化学与生物技术重点实验室开放基金 (No. 2019KF06)、广西高等学校千名中青年骨干教师培育计划、广西高校中青年科研基础能力提升项目(No. 2019KY051)和桂林医学院中青年教职工 科研基础能力提升(No. 2018glmcy015)资助项目.
} 


\section{Introduction}

Rosins are the solid form of resins obtained from pines or similar types of plants belonging to the conifer family and they are important natural resources of China. Pine resin acids are the main components of rosin, and they have generated signcant interest from the medicinal, pharmacological and forestry communities for their wide variety of interesting biological activities. ${ }^{[1]}$ Dehydroabietic acid (DHAA) is a natural occurring diterpenic resin acid which can be easily obtained from Pinus rosin or from commercial disproportionated rosin. ${ }^{[2]}$ DHAA and its derivatives exhibited extensive pharmaceutical activities, such as antitumor, ${ }^{[3-7]}$ antimicrobial, ${ }^{[8-10]}$ antiprotozoal, ${ }^{[11]}$ antiviral, ${ }^{[12]}$ antifungal, ${ }^{[13-14]}$ gastroprotective, ${ }^{[15]}$ insecticidal $^{[16]}$ anti-inflammatory ${ }^{[17]}$ antiulcer, ${ }^{[18]}$ and anxiolytic ${ }^{[19]}$ activities. Furthermore, DHAA was reported to show properties of enhancing the inhibitory activity of an anticancer drug in cervical carcinoma cells, hepatocellular carcinoma cells, or breast cancer cells. These results suggest that DHAA is a promising starting material for the discovery of novel anticancer agents.

In previous study, numerous reports demonstrate that nitric oxide (NO) is a multifunctional signaling and/or effector molecule with numerous functions in vasodilation, neurotransmission, the immune system, and cell apoptosis. ${ }^{[20-21]}$ It has been shown that high levels of NO can directly kill tumor cells, induce tumor cell apoptosis, impair tumor cell proliferation and invasion ability via nitric oxide-releasing, and prevent tumor cells from metastasizing and increase tumor cell response to radiochemotherapy. Particularly, it is reported that numerous NO-donating hybrids have the potential to provide novel anticancer candidates with low toxicity and high efficacy against drug-resistant cancers. ${ }^{[22-27]}$
Enlightened by these findings, together with our previous studies on the modification of natural products, ${ }^{[28-31]}$ a modification via integrating DHAA and nitrate pharmacophore into one molecule to generate a novel dehydroabietic acid NO donor hybrids was conducted. The screening of the cytotoxicity of these hybrids against four human cancer cell lines and normal human cell were carried on. The NO released amounts of these hybrids by Griess assay to investigate the relationship between NO released amounts and cytotoxic activities were also detected.

\section{Results and discussion}

\subsection{Synthesis and characterization}

The synthetic route of these compounds is depicted in Scheme 1. Using dehydroabietic acid as starting material, the key intermediates 12-bromodehydroabietic acid (2) and 12,14-dinitrodehydroabietic acid (3) were synthesized by reaction of DHAA with bromides and fuming nitric acid, respectively. Then they reacted with dibromohydrocarbon and silver nitrate to obtain the dehydroabietic acid-nitrate conjugates $\mathbf{5 a} \sim \mathbf{5 r}$ in a good yield. Synthetic compounds $\mathbf{5}$ need to be carried out protected from light.

The FT-IR spectra of target compounds $\mathbf{5 a} \sim \mathbf{5} \mathbf{r}$ exhibited characteristic moderate absorption bands at about 1720 $\mathrm{cm}^{-1}$ attributed to the stretching vibrations of $\mathrm{C}=\mathrm{O}$. The bands at about 1630 and $1280 \mathrm{~cm}^{-1}$ were attributed to the stretching vibration of $\mathrm{ONO}_{2}$. The bands at $1600 \sim 1450$ $\mathrm{cm}^{-1}$ were assigned to the vibration of the skeleton in benzene rings. The bands at $2950 \sim 2800 \mathrm{~cm}^{-1}$ were assigned to the stretching vibrations of $\mathrm{C}-\mathrm{H}$ in methyl or methylene. The ${ }^{1} \mathrm{H}$ NMR spectra of the target compounds $\mathbf{5 a} \sim \mathbf{5 r}$ showed characteristic signals at $\delta 7.56 \sim 6.89$ assigned to the aromatic protons. The ${ }^{13} \mathrm{C}$ NMR spectra of the target compounds $\mathbf{5 a} \sim \mathbf{5} \mathbf{r}$ showed peaks for $\mathrm{C}=\mathrm{O}$ at $\delta$ $179 \sim 177$, and for benzene rings at $\delta 152 \sim 121$.

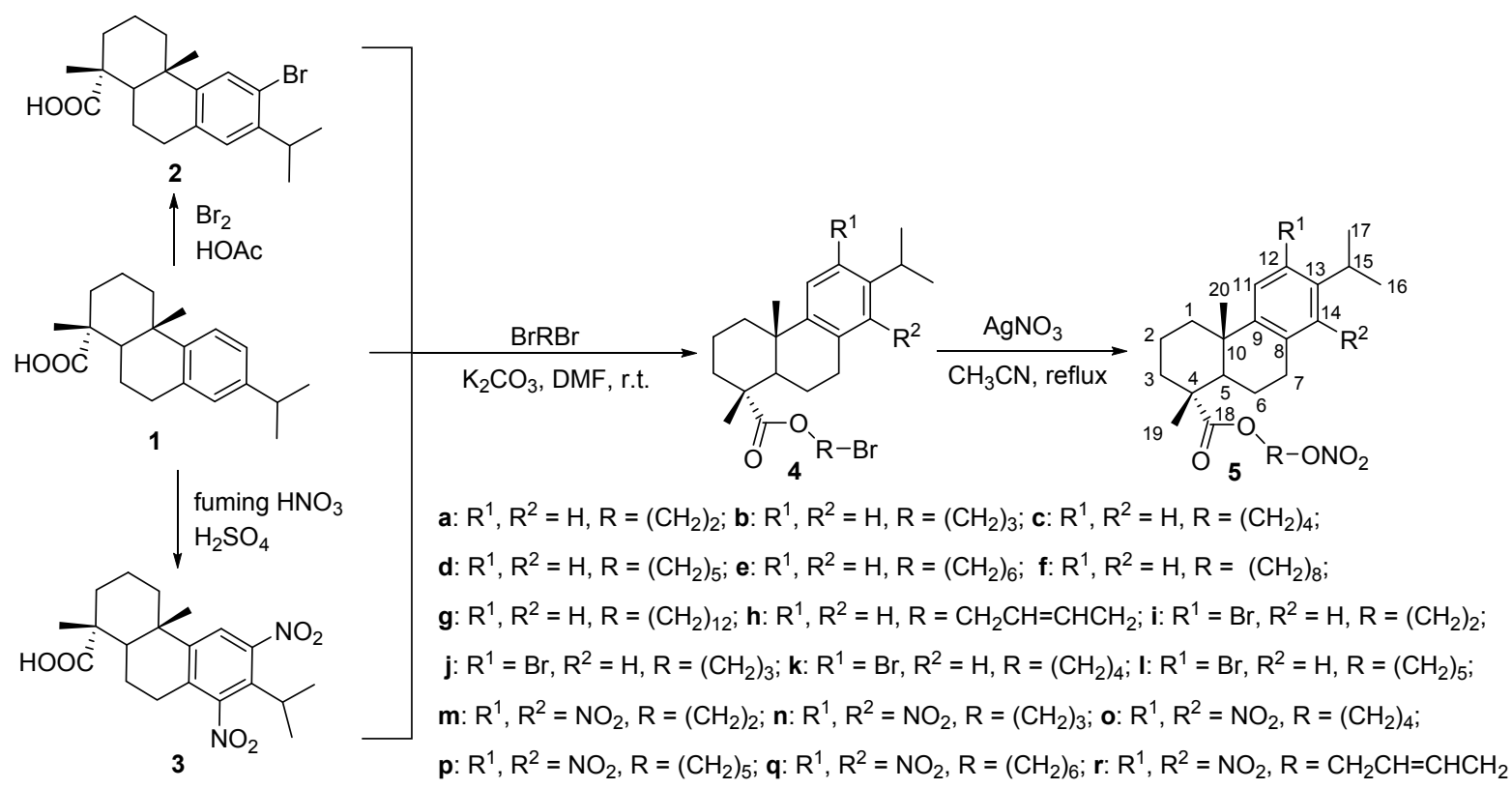

Scheme 1 Synthetic route for dehydroabietic acid-based nitrate compounds $\mathbf{5 a} \sim \mathbf{5 r}$ 


\subsection{Evaluation of cytotoxicity}

Given that nasopharyngeal carcinoma, liver cancer and cervical cancer are very common cancer types, CNE-2, HepG2, BEL-7402 and HeLa cells were chosen. (3-(4,5Dimethylthiazol-2-yl)-2,5-diphenyltetrazolium bromide (MTT) assay was applied to determine the effects of dehydroabietic acid nitrates on the growth inhibition against cancer cells. The results were listed in Table 1.

As tabulated in Table 1, most of dehydroabietic acid nitrates were more potent than the parent compounds dehydroabietic acid and displayed moderate cytotoxicity effects. It is found that compounds $\mathbf{5} \mathbf{j}$ and $\mathbf{5 n}$ showed significant inhibition enhancement against CNE-2 and BEL7402, respectively. Compared with DHAA, the inhibition activity of $\mathbf{5 j}$ against CNE-2 was increased by 10 times with $\mathrm{IC}_{50}$ value of $(8.36 \pm 0.14) \mu \mathrm{mol} / \mathrm{L}$, which was the most active compound against $\mathrm{CNE}-2$ cancer cell amongst all the tested derivatives; While $\mathbf{5 n}$ exhibited the best inhibition activity against BEL-7402 cancer cells with $\mathrm{IC}_{50}$ value of $(11.23 \pm 0.21) \mu \mathrm{mol} / \mathrm{L}$, which was more active than cisplatin. Most impressively, the cytotoxicity of dehydroabietic acid nitrates is dependent on the length, kind of linkers and the substituent in benzene ring. For both CNE-2 and HepG2 cancer cells, the cytotoxicity of nitrate with unsaturated carbon chains is slightly better than that of saturated carbon chains, and the compounds with bromine substitution at position-12 exhibited greater potency than without substituents. The most of compounds with nitro substitution at position-12 and position-14 exhibited significant inhibition enhancement against the growth of all the tested cancer cells. Compound $\mathbf{5 k}$ showed the best inhibition activity against $\mathrm{HepG} 2$ with $\mathrm{IC}_{50}$ value of $(8.83 \pm 0.65) \mu \mathrm{mol} / \mathrm{L}$, which was 9 times more active than the parent compound. Futhermore, it was found that the cytotoxicities of dehydroabietic acid-nitrate hybrid molecules against human normal liver cell line HL-7702 and nasopharyngeal epithelial cell NP69 are low, in which the $\mathrm{IC}_{50}$ values are over $(65.28 \pm 0.35) \mu \mathrm{mol} / \mathrm{L}$.

\subsection{Evaluation of $\mathrm{NO}$ release}

To explore the association between NO release amounts of these nitrates and their cytotoxic activity, the NO release levels of these nitrates in vitro were detected using nitrate/nitrite assay. Thus, we decided to evaluate the cellular levels of $\mathrm{NO}$ of all nitrates at $4 \mathrm{mmol} / \mathrm{L}$ for $24 \mathrm{~h}$. As shown in Figure 1, it was observed that the nitrates designed in this study could produce different levels of NO intracellularly which generally agreed with the cytotoxic activity.

\section{Conclusions}

In conclusion, eighteen novel nitrates derivatives have been designed and synthesized using dehydroabietic acid as a starting material. All the compounds were confirmed with FT-IR, ESI-MS, ${ }^{1} \mathrm{H}$ NMR, ${ }^{13} \mathrm{C}$ NMR and elemental analysis. Their cytotoxic activities against CNE-2, HepG2, BEL-7402 and HeLa cancer cell lines were determined. The preliminary bioassay showed that compound $\mathbf{5 j}$ was demonstrated as the most potent inhibitor against CNE-2

Table 1 Cytotoxic activity of dehydroabietic acid-based nitrate compounds

\begin{tabular}{|c|c|c|c|c|c|c|}
\hline \multirow{2}{*}{ Compd. } & \multicolumn{6}{|c|}{$\mathrm{IC}_{50}{ }^{a} /\left(\mu \mathrm{mol} \cdot \mathrm{L}^{-1}\right)$} \\
\hline & CNE-2 & HepG2 & BEL-7402 & $\mathrm{HeLa}$ & HL-7702 & NP69 \\
\hline DHAA & $88.64 \pm 0.73$ & $80.36 \pm 0.84$ & $46.70 \pm 0.55$ & $37.40 \pm 0.64$ & $>100$ & $>100$ \\
\hline $4 \mathbf{i}$ & $75.84 \pm 1.42$ & $61.55 \pm 0.37$ & $53.18 \pm 1.83$ & $88.28 \pm 3.12$ & $>100$ & $>100$ \\
\hline $4 j$ & $60.33 \pm 2.54$ & $45.96 \pm 0.77$ & $69.24 \pm 1.63$ & $73.04 \pm 1.08$ & $>100$ & $>100$ \\
\hline $4 k$ & $42.29 \pm 0.86$ & $57.58 \pm 1.26$ & $48.35 \pm 0.48$ & $50.28 \pm 0.57$ & $>100$ & $>100$ \\
\hline $5 \mathbf{a}$ & $43.88 \pm 0.15$ & $50.44 \pm 0.08$ & $38.25 \pm 0.44$ & $44.32 \pm 0.28$ & $>100$ & $>100$ \\
\hline $5 \mathbf{b}$ & $35.64 \pm 0.48$ & $66.93 \pm 0.20$ & $42.11 \pm 0.64$ & $38.12 \pm 0.15$ & $>100$ & $>100$ \\
\hline $5 c$ & $33.09 \pm 0.23$ & $57.34 \pm 0.15$ & $24.02 \pm 0.62$ & $40.10 \pm 0.23$ & $>100$ & $>100$ \\
\hline $5 d$ & $36.32 \pm 0.57$ & $34.62 \pm 0.17$ & $32.22 \pm 0.37$ & $33.44 \pm 0.72$ & $>100$ & $>100$ \\
\hline $5 e$ & $20.63 \pm 0.66$ & $25.84 \pm 0.22$ & $50.78 \pm 0.32$ & $14.14 \pm 0.21$ & $>100$ & $>100$ \\
\hline $5 f$ & $25.44 \pm 0.74$ & $21.94 \pm 0.54$ & $14.88 \pm 0.30$ & $27.34 \pm 0.64$ & $>100$ & $>100$ \\
\hline $5 g$ & $27.26 \pm 0.55$ & $30.17 \pm 0.32$ & $18.40 \pm 0.24$ & $67.33 \pm 0.46$ & $>100$ & $>100$ \\
\hline $5 \mathrm{~h}$ & $18.20 \pm 0.16$ & $20.46 \pm 0.18$ & $17.52 \pm 0.64$ & $55.45 \pm 0.40$ & $74.39 \pm 0.19$ & $89.35 \pm 0.56$ \\
\hline $5 \mathbf{i}$ & $34.16 \pm 0.43$ & $30.64 \pm 0.24$ & $44.72 \pm 0.46$ & $65.15 \pm 0.74$ & $>100$ & $>100$ \\
\hline $5 \mathbf{j}$ & $8.36 \pm 0.14$ & $13.00 \pm 0.61$ & $55.33 \pm 0.42$ & $23.36 \pm 0.44$ & $>100$ & $>100$ \\
\hline $5 k$ & $16.84 \pm 0.34$ & $8.83 \pm 0.65$ & $35.14 \pm 0.13$ & $12.06 \pm 0.52$ & $87.66 \pm 0.43$ & $>100$ \\
\hline $\mathbf{5 l}$ & $22.33 \pm 0.56$ & $15.29 \pm 0.42$ & $38.78 \pm 0.36$ & $7.88 \pm 0.58$ & $>100$ & $>100$ \\
\hline $5 \mathrm{~m}$ & $9.24 \pm 0.40$ & $34.88 \pm 0.10$ & $32.47 \pm 0.42$ & $8.42 \pm 0.70$ & $>100$ & $>100$ \\
\hline $5 n$ & $66.89 \pm 0.67$ & $10.40 \pm 0.27$ & $11.23 \pm 0.21$ & $15.16 \pm 0.81$ & $88.18 \pm 0.23$ & $>100$ \\
\hline 50 & $25.00 \pm 0.11$ & $30.53 \pm 0.82$ & $14.66 \pm 0.40$ & $42.51 \pm 0.18$ & $>100$ & $>100$ \\
\hline $5 p$ & $15.66 \pm 0.42$ & $22.08 \pm 0.45$ & $44.05 \pm 0.30$ & $14.06 \pm 0.16$ & $>100$ & $>100$ \\
\hline $5 q$ & $9.63 \pm 0.33$ & $13.90 \pm 0.16$ & $33.88 \pm 0.08$ & $4.57 \pm 0.41$ & $65.28 \pm 0.35$ & $92.86 \pm 0.75$ \\
\hline $5 r$ & $20.87 \pm 0.08$ & $28.66 \pm 0.43$ & $18.93 \pm 0.37$ & $34.78 \pm 0.13$ & $>100$ & $>100$ \\
\hline Cisplatin & $8.75 \pm 0.24$ & $6.42 \pm 0.18$ & $12.68 \pm 0.33$ & $1.94 \pm 0.20$ & $20.76 \pm 0.83$ & $10.74 \pm 0.52$ \\
\hline
\end{tabular}

${ }^{a}$ Data represent the means \pm S.D. from three independent experiments. 


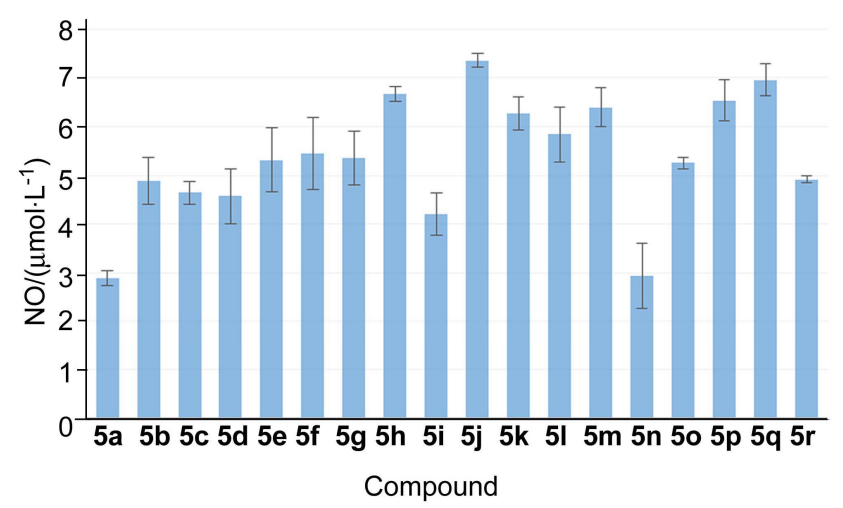

Figure 1 NO released amounts of the target compounds in CNE-2 cells for $24 \mathrm{~h}$ (mean $\pm \mathrm{SD}, n=3$ )

cell line with $\mathrm{IC}_{50}$ value of $(8.36 \pm 0.14) \mu \mathrm{mol} / \mathrm{L}$; while $5 \mathbf{n}$ was confirmed as the most potent agent against BEL-7402 cancer cells with $\mathrm{IC}_{50}$ value of $(11.23 \pm 0.21) \mu \mathrm{mol} / \mathrm{L}$. NO released amounts revealed that the potent compounds which exhibited high cytotoxic activities consistently produced high levels of NO in CNE-2. Therefore, the nitrate-hybrids could be a promising strategy for the synthesis of antitumor dehydroabietic acid derivatives.

\section{Experimental section}

\subsection{General}

All the chemicals and reagents were commercially available and used without further purification. Routine thin-layer chromatography (TLC) was performed on silica gel plates (silica gel GF254 from Qingdao Haiyang Chemical Co., Ltd., Qingdao, China), preparative flash column chromatography was performed on the $200 \sim 300$ mesh silica gel (Qingdao Haiyang Chemical Co. Ltd., Qingdao, Shandong, China). Melting points were recorded on an X-4 microscope melting point apparatus (Beijing Tech Instrument Co., Ltd., Beijing, China) without calibration. ${ }^{1} \mathrm{H}$ NMR and ${ }^{13} \mathrm{C}$ NMR spectra were recorded on a Bruker Avance III HD $600 \mathrm{MHz}$ spectrometer (Bruker Co., Ltd., Zurich, Switzerland) at room temperature with TMS as an internal standard and $\mathrm{CDCl}_{3}$ as solvents. Mass spectra were recorded on a liquid chromatograph mass spectrometer (Shimazu Co. Ltd., Kyoto, Japan). Elemental analyses were carried out on a PE 2400II elemental analyzer (Perkin Elmer Instruments Co., Ltd., USA). The optical density was measured on a microplate reader (BioTek Instruments Co., Ltd., USA).

\subsection{Synthesis}

\subsubsection{Synthetic route for intermediates 2}

According to literature method, ${ }^{[32]}$ dehydroabietic acid (12.0 g, $40 \mathrm{mmol}$ ) was dissolved in glacial acetic acid (40 $\mathrm{mL})$, then bromine $(3.2 \mathrm{~mL})$ dissolved in glacial acetic acid $(20 \mathrm{~mL})$ was added slowly to the above solution. The reaction solution continued stirring for $3 \mathrm{~h}$ at room temperature. Standing overnight, the reaction $(\mathrm{pH}=6)$ was adjusted with concentrated ammonia water, the sediments was filtered and recrystallized with $65 \%$ ethanol $(50 \mathrm{~mL})$ to obtain compound 2 (yield $63.8 \%$ ).

\subsubsection{Synthetic route for intermediates 3}

According to literature method, ${ }^{[33]}$ to a mixture of concentrated sulfuric acid $(60 \mathrm{~mL})$ and fuming nitric acid (40 $\mathrm{mL})$ cooled in ice bath, dehydroabietic acid (14 g) was added in batches. The mixture was stirred and allowed to come to room temperature. After completion of the reaction, the mixture slowly poured into $900 \mathrm{~mL}$ of ice water. Standing overnight, the reaction was drained and washed with distilled water until neutral. The crude products were recrystallized with ethanol three times to give compound $\mathbf{3}$ (yield 70.4\%).

\subsubsection{Synthetic route for intermediates $\mathbf{4 a} \sim \mathbf{4 r}$}

1,12-Bromodehydroabietic acid (2) or 12,14-dinitrodehydroabietic acid (3) (21.12 $\mathrm{mmol})$, dibromoalkane (40.00 $\mathrm{mmol})$, and anhydrous $\mathrm{K}_{2} \mathrm{CO}_{3}(2.91 \mathrm{~g})$ were added to 40 $\mathrm{mL}$ of $N, N$-dimethylformamide (DMF) and stired for $6 \mathrm{~h}$ at $40{ }^{\circ} \mathrm{C}$. After the reaction, the mixture was poured into cold water and extracted with ethyl acetate $(40 \mathrm{~mL} \times 3)$, and then the combined organic layer was washed with saturated salt water and dried $\left(\mathrm{Na}_{2} \mathrm{SO}_{4}\right)$ overnight. The solution was concentrated with a rotary evaporator, the intermediates $4 \mathbf{a} \sim 4 \mathbf{r}$ were purified by silica gel chromatography with a mixture of petroleum ether and ethyl acetate $(V: V=20: 1)$ as eluent.

Dehydroabietic acid-2'-bromoethyl ester (4a): White solid, yield 78.6\%. m.p. 46.2 49.4 ${ }^{\circ} \mathrm{C} ;{ }^{1} \mathrm{H}$ NMR $(600$ $\left.\mathrm{MHz}, \mathrm{CDCl}_{3}\right) \delta: 7.22(\mathrm{~d}, J=8.4 \mathrm{~Hz}, 1 \mathrm{H}, \mathrm{H}-11), 7.06$ (d, $J=8.4 \mathrm{~Hz}, 1 \mathrm{H}, \mathrm{H}-12), 6.95$ (s, 1H, H-14), $4.50 \sim 4.37$ (m, $2 \mathrm{H}, \mathrm{H}-21), 3.57 \sim 3.54$ (t, $J=6.0 \mathrm{~Hz}, 2 \mathrm{H}, \mathrm{H}-22), 3.01 \sim$ 2.97 (m, 1H, H-15), $2.94 \sim 2.85$ (m, 2H, H-7), $2.33 \sim 2.37$ $(\mathrm{m}, 2 \mathrm{H}, \mathrm{He}-1, \mathrm{H}-5), 1.92 \sim 1.71(\mathrm{~m}, 5 \mathrm{H}, \mathrm{H}-2, \mathrm{H}-3$ and He-6), $1.47 \sim 1.57$ (m, 2H, Нa-1, Ha-6), 1.35 (s, 3H, H-19), 1.28 (s, 3H, H-20), 1.27 (d, $J=1.8 \mathrm{~Hz}, 6 \mathrm{H}, \mathrm{H}-16$ and $\mathrm{H}-17) ;{ }^{13} \mathrm{C}$ NMR (150 MHz, $\left.\mathrm{CDCl}_{3}\right) \delta: 179.6,148.2$, 147.2 , 136.1, 128.4, 125.6, 125.4, 65.5, 49.3, 46.1, 39.4, $38.4,38.1,34.9,30.5,25.5,23.3,20.1,18.0$; IR (KBr) $v$ : 2867, $1733(\mathrm{C}=\mathrm{O}), 1496,1498,1387,1243,1172,1006$, $821,682 \mathrm{~cm}^{-1}$. Anal. calcd for $\mathrm{C}_{22} \mathrm{H}_{31} \mathrm{BrO}_{2}$ : C 64.86, $\mathrm{H}$ 7.67; found C 64.79, H 7.63.

Dehydroabietic acid-3'-bromopropyl ester (4b): Colorless liquid, yield 75.4\%. ${ }^{1} \mathrm{H}$ NMR $\left(600 \mathrm{MHz}, \mathrm{CDCl}_{3}\right) \delta$ : $7.20(\mathrm{~d}, J=8.2 \mathrm{~Hz}, 1 \mathrm{H}, \mathrm{H}-11), 7.04$ (d, $J=8.1 \mathrm{~Hz}, 1 \mathrm{H}$, H-12), 6.92 (s, 1H, H-14), 4.24 (ddd, $J=17.5,11.0,5.3$ $\mathrm{Hz}, 2 \mathrm{H}, \mathrm{H}-21), 3.47$ (t, $J=6.5 \mathrm{~Hz}, 2 \mathrm{H}, \mathrm{H}-23), 2.91$ (dd, $J=10.6,5.3 \mathrm{~Hz}, 2 \mathrm{H}, \mathrm{H}-7), 2.86$ (dt, $J=13.8,7.0 \mathrm{~Hz}, 1 \mathrm{H}$, H-15), 2.34 (d, $J=12.8 \mathrm{~Hz}, 1 \mathrm{H}, \mathrm{He}-1), 2.26$ (dd, $J=12.5$, $2.1 \mathrm{~Hz}, 1 \mathrm{H}, \mathrm{H}-5), 2.22 \sim 2.17$ (m, 2H, H-22), $1.94 \sim 1.69$ (m, 5H, H-2, H-3, He-6), 1.53 (t, $J=12.5 \mathrm{~Hz}, 1 \mathrm{H}, \mathrm{Ha}-1)$, 1.43 (dtd, $J=8.0,6.0,2.5 \mathrm{~Hz}, 1 \mathrm{H}, \mathrm{Ha}-6), 1.31$ (s, 3H, H-19), 1.26 (d, $J=1.8 \mathrm{~Hz}, 6 \mathrm{H}, \mathrm{H}-16, \mathrm{H}-17), 1.24$ (s, 3H, $\mathrm{H}-20) ;{ }^{13} \mathrm{C}$ NMR $\left(150 \mathrm{MHz}, \mathrm{CDCl}_{3}\right) \delta: 178.4,146.8$, $145.8,134.6,127.0,124.2,124.0,62.3,47.8,44.9,37.9$, $37.0,36.7,33.6,33.5,31.7,31.6,30.1,29.5,25.3,24.5$, 24.0, 21.8, 18.6, 16.5; IR (KBr) v: 2916, $1724(\mathrm{C}=\mathrm{O})$, 
$1498,1458,1385,1238,1174,1125,1037,883,822 \mathrm{~cm}^{-1}$ Anal. calcd for $\mathrm{C}_{23} \mathrm{H}_{33} \mathrm{BrO}_{2}$ : C 65.55, $\mathrm{H} \mathrm{7.89}$; found $\mathrm{C}$ 65.58, H 7.84.

Dehydroabietic acid-4'-bromobutyl ester (4c): Colorless liquid, yield $74.3 \%$. ${ }^{1} \mathrm{H}$ NMR $\left(600 \mathrm{MHz}, \mathrm{CDCl}_{3}\right) \delta: 7.17$ (d, $J=8.4 \mathrm{~Hz}, 1 \mathrm{H}, \mathrm{H}-11), 7.01$ (d, $J=8.4 \mathrm{~Hz}, 1 \mathrm{H}, \mathrm{H}-12)$, 6.90 (s, 1H, H-14), $4.15 \sim 4.06(\mathrm{~m}, 2 \mathrm{H}, \mathrm{H}-21), 3.43(\mathrm{t}, J=$ $6.0 \mathrm{~Hz}, 2 \mathrm{H}, \mathrm{H}-24), 2.89 \sim 2.87(\mathrm{~m}, 2 \mathrm{H}, \mathrm{H}-7), 2.86 \sim 2.81$ (m, 1H, H-15), 2.30 (d, $J=12.0 \mathrm{~Hz}, 1 \mathrm{H}, \mathrm{He}-1), 2.25(\mathrm{~d}, J=$ $12.0 \mathrm{~Hz}, 1 \mathrm{H}, \mathrm{H}-5), 1.95 \sim 1.93$ (m, 2H, H-22), $1.86 \sim 1.63$ (m, 7H, H-2, H-3, He-6, H-23), $1.52 \sim 1.48$ (m, 1H, Нa-1), $1.42 \sim 1.39$ (m, 1H, Ha-6), 1.28 (s, 3H, H-19), $1.23 \sim 1.24$ (d, $J=7.2 \mathrm{~Hz}, 6 \mathrm{H}, \mathrm{H}-16, \mathrm{H}-17), 1.22$ (s, 3H, H-20); ${ }^{13} \mathrm{C}$ NMR $\left(150 \mathrm{MHz}, \mathrm{CDCl}_{3}\right) \delta: 178.5,146.9,145.8,134.6$, 127.0, 124.2, 124.0, 64.0, 63.6, 47.7, 44.8, 38.0, 37.0, 36.7, $33.5,33.0,30.129 .3,27.4,25.5,25.3,24.0,21.8,18.6$, 16.6; IR (KBr) v: 2933, $1722(\mathrm{C}=\mathrm{O}), 1496,1463,1384$, $1246,1174,1126,1035,887,823 \mathrm{~cm}^{-1}$. Anal. calcd for $\mathrm{C}_{24} \mathrm{H}_{35} \mathrm{BrO}_{2}$ : C 66.20, $\mathrm{H}$ 8.10; found C 66.25, H 8.12.

Dehydroabietic acid-5'-bromoamyl ester (4d): Colorless liquid, yield $80.4 \% .{ }^{1} \mathrm{H}$ NMR $\left(600 \mathrm{MHz}, \mathrm{CDCl}_{3}\right) \delta: 7.20$ (d, $J=8.4 \mathrm{~Hz}, 1 \mathrm{H}, \mathrm{H}-11), 7.03$ (d, $J=8.4 \mathrm{~Hz}, 1 \mathrm{H}, \mathrm{H}-12)$, $6.92(\mathrm{~s}, 1 \mathrm{H}, \mathrm{H}-14), 4.15 \sim 4.06(\mathrm{~m}, 2 \mathrm{H}, \mathrm{H}-21), 4.44 \sim 3.42$ $(\mathrm{m}, 2 \mathrm{H}, \mathrm{H}-25), 2.91 \sim 2.83(\mathrm{~m}, 3 \mathrm{H}, \mathrm{H}-7, \mathrm{H}-15), 2.32$ (d, $J=11.4 \mathrm{~Hz}, 1 \mathrm{H}, \mathrm{He}-1), 2.26$ (d, $J=12.0 \mathrm{~Hz}, 1 \mathrm{H}, \mathrm{H}-5)$, $1.94 \sim 1.54(\mathrm{~m}, 11 \mathrm{H}, \mathrm{H}-2, \mathrm{H}-3, \mathrm{He}-6, \mathrm{H}-22, \mathrm{H}-23$ and $\mathrm{H}-24), 1.45 \sim 1.35(\mathrm{~m}, 2 \mathrm{H}$, Ha-1 and Ha-6), $1.30(\mathrm{~s}, 3 \mathrm{H}$, $\mathrm{H}-19), 1.24 \sim 1.26(\mathrm{~m}, 9 \mathrm{H}, \mathrm{H}-16, \mathrm{H}-17$ and $\mathrm{H}-20) ;{ }^{13} \mathrm{C}$ NMR $\left(150 \mathrm{MHz}, \mathrm{CDCl}_{3}\right) \delta: 178.6,146.9,145.7,134.7$, $126.9,124.2,124.0,64.2,47.7,44.8,38.0,37.0,36.7,33.5$, $33.4,30.1,25.2,24.7,24.0,21.8,18.6$ 16.5; IR (KBr) $v$ : 2908, $1722(\mathrm{C}=\mathrm{O}), 1496,1463,1388,1246,1174,1126$, $1035,887,823,723 \mathrm{~cm}^{-1}$. Anal. calcd for $\mathrm{C}_{25} \mathrm{H}_{37} \mathrm{BrO}_{2}: \mathrm{C}$ 66.81, H 8.30; found C 66.77, H 8.26.

Dehydroabietic acid-6'-bromohexyl ester (4e): Colorless liquid, yield $58.6 \%$. ${ }^{1} \mathrm{H}$ NMR $\left(600 \mathrm{MHz}, \mathrm{CDCl}_{3}\right) \delta: 7.20$ (d, $1 \mathrm{H}, J=8.1 \mathrm{~Hz}, \mathrm{H}-11), 7.03$ (d, $1 \mathrm{H}, J=8.1 \mathrm{~Hz}, \mathrm{H}-12)$, 6.91 (s, 1H, H-14), $4.14 \sim 4.06$ (m, 2H, H-21), 3.45 3.41 (m, 2H, H-26), 2.90 (dd, J=8.9, $4.3 \mathrm{~Hz}, 2 \mathrm{H}, \mathrm{H}-7), 2.85$ $(\mathrm{dt}, J=13.8,6.9 \mathrm{~Hz}, 1 \mathrm{H}, \mathrm{H}-15), 2.33$ (d, $1 \mathrm{H}, J=12.2 \mathrm{~Hz}$, He-1), 2.27 (dd, $J=12.5,2.0 \mathrm{~Hz}, 1 \mathrm{H}, \mathrm{H}-5), 1.89 \sim 1.42(\mathrm{~m}$, $15 \mathrm{H}, \mathrm{Ha}-1, \mathrm{H}-2, \mathrm{H}-3, \mathrm{H}-6, \mathrm{H}-22, \mathrm{H}-23, \mathrm{H}-24$ and H-25), 1.29 (s, 3H, H-19), 1.25 (d, $J=6.9 \mathrm{~Hz}, 6 \mathrm{H}, \mathrm{H}-16$ and $\mathrm{H}-17), 1.24$ (s, 3H, H-20); ${ }^{13} \mathrm{C}$ NMR (150 MHz, $\left.\mathrm{CDCl}_{3}\right) \delta$ : 178.6, 147.0, 145.7, 134.7, 126.9, 124.2, 124.0, 64.5, 47.7, $44.8,38.0,37.0,36.7,33.7,33.5,32.6,30.2,28.5,27.8$, $25.3,24.0,21.8,18.6,16.5$; IR (KBr) v: 2933, $1722(\mathrm{C}=$ O), $1462,1384,1246,1176,1126,1007,975,825,726$

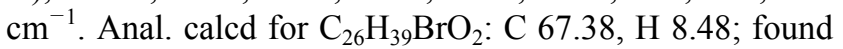
C 67.37, H 8.51.

Dehydroabietic acid-8'-bromooctyl ester (4f): Colorless liquid, yield $72.8 \%$. ${ }^{1} \mathrm{H}$ NMR $\left(600 \mathrm{MHz}, \mathrm{CDCl}_{3}\right) \delta: 7.11$ (d, $J=8.2 \mathrm{~Hz}, 1 \mathrm{H}, \mathrm{H}-11), 6.93$ (d, $J=8.4 \mathrm{~Hz}, 1 \mathrm{H}, \mathrm{H}-12)$, $6.82(\mathrm{~s}, 1 \mathrm{H}, \mathrm{H}-14), 4.05 \sim 3.91(\mathrm{~m}, 2 \mathrm{H}, \mathrm{H}-21), 3.33$ (q, $J=$ $6.8,6.8 \mathrm{~Hz}, 2 \mathrm{H}, \mathrm{H}-28), 2.82 \sim 2.72$ (m, 3H, H-7 and H-15), $2.23(\mathrm{~d}, J=12.6 \mathrm{~Hz}, 1 \mathrm{H}, \mathrm{He}-1), 2.18$ (dd, $J=12.5,1.9 \mathrm{~Hz}$, 1H, H-5), $1.82 \sim 1.25$ (m, 19H, Ha-1, H-2, H-3, H-6, H-22,
H-23, H-24, H-25, H-26 and H-27), 1.19 (s, 3H, H-19), $1.16(\mathrm{~s}, 3 \mathrm{H}, \mathrm{H}-20), 1.14(\mathrm{~d}, J=3.1 \mathrm{~Hz}, 6 \mathrm{H}, \mathrm{H}-16$ and $\mathrm{H}-17) ;{ }^{13} \mathrm{C}$ NMR $\left(150 \mathrm{MHz}, \mathrm{CDCl}_{3}\right) \delta: 178.7,147.0$, $145.7,134.7,126.9,124.2,124.0,64.6,47.7,44.8,38.0$, $37.0,36.6,34.0,33.5,32.8,30.2,29.0,28.6,28.6,28.6$, 28.1, 25.9, 25.3, 24.0, 21.8, 18.7, 16.5; IR (KBr) v: 2929, 2860, $1722(\mathrm{C}=\mathrm{O}), 1496,1462,1382,1244,1176,1124$, $1035,975,823 \mathrm{~cm}^{-1}$. Anal. calcd for $\mathrm{C}_{28} \mathrm{H}_{43} \mathrm{BrO}_{2}$ : C 68.42, H 8.82; found C $68.45, \mathrm{H} 8.86$.

Dehydroabietic acid-12'-bromodecyl ester (4g): Colorless liquid, yield $62.8 \%$. ${ }^{1} \mathrm{H}$ NMR $\left(600 \mathrm{MHz}, \mathrm{CDCl}_{3}\right) \delta$ : $7.20(\mathrm{~d}, J=8.2 \mathrm{~Hz}, 1 \mathrm{H}, \mathrm{H}-11), 7.03$ (d, $J=8.2 \mathrm{~Hz}, 1 \mathrm{H}$, H-12), 6.91 (s, 1H, H-14), 4.08 (dq, $J=17.4,6.6 \mathrm{~Hz}, 2 \mathrm{H}$, H-21), 3.43 (t, $J=6.9 \mathrm{~Hz}, 2 \mathrm{H}, \mathrm{H}-32), 2.90$ (dd, $J=10.8$, $5.2 \mathrm{~Hz}, 2 \mathrm{H}, \mathrm{H}-7), 2.85$ (dt, $J=13.8,7.0 \mathrm{~Hz}, 1 \mathrm{H}, \mathrm{H}-15)$, $2.33(\mathrm{~d}, J=12.2 \mathrm{~Hz}, 1 \mathrm{H}, \mathrm{He}-1), 2.28(\mathrm{dd}, J=12.5,2.0 \mathrm{~Hz}$, $1 \mathrm{H}, \mathrm{H}-5), 1.91 \sim 1.29$ (m, 30H, Ha-1, H-2, H-3, H-6, H-19, H-22, H-23, H-24, H-25, H-26, H-27, H-28, H-29, H-30 and H-31), 1.25 (d, $J=6.9 \mathrm{~Hz}, 6 \mathrm{H}, \mathrm{H}-16, \mathrm{H}-17), 1.24$ (s, $3 \mathrm{H}, \mathrm{H}-20) ;{ }^{13} \mathrm{C} \mathrm{NMR}\left(150 \mathrm{MHz}, \mathrm{CDCl}_{3}\right) \delta: 178.7,147.0$, $145.7,134.7,127.9,124.2,123.9,64.7,47.7,44.8,38.0$, $37.0,36.6,34.1,33.5,32.9,30.2,29.5,29.5,29.4,29.2$, $28.8,28.7,28.2,26.0,25.3,24.0,21.8,18.7,16.5$; IR $(\mathrm{KBr}) v: 3074,2954,2872,1724(\mathrm{C}=\mathrm{O}), 1490,1460$, 1382, 1242, 1176, 1122, 1035, 981, 916, $823 \mathrm{~cm}^{-1}$. Anal. calcd for $\mathrm{C}_{32} \mathrm{H}_{51} \mathrm{BrO}_{2}$ : C 70.18, $\mathrm{H}$ 9.39; found $\mathrm{C} 70.15, \mathrm{H}$ 9.42 .

Dehydroabietic acid-4'-bromobutenyl ester (4h): Colorless liquid, yield 53.7\%. ${ }^{1} \mathrm{H}$ NMR (600 $\left.\mathrm{MHz} \mathrm{CDCl}_{3}\right) \delta$ : 7.23 (s, 1H, H-11), 7.06 (d, J=8.0 Hz, 1H, H-12), 6.94 (s, $1 \mathrm{H}, \mathrm{H}-14), 5.83$ (dd, $J=17.1,10.3 \mathrm{~Hz}, 2 \mathrm{H}, \mathrm{H}-22, \mathrm{H}-23$ ), $5.13(\mathrm{dd}, J=24.5,13.7 \mathrm{~Hz}, 2 \mathrm{H}, \mathrm{H}-21), 4.18$ (td, $J=17.4$, $6.7 \mathrm{~Hz}, 2 \mathrm{H}, \mathrm{H}-24), 2.95 \sim 2.86(\mathrm{~m}, 3 \mathrm{H}, \mathrm{H}-7$ and $\mathrm{H}-15)$, $2.35(\mathrm{~d}, J=12.3 \mathrm{~Hz}, 1 \mathrm{H}, \mathrm{He}-1), 2.31(\mathrm{~d}, J=11.2 \mathrm{~Hz}, 1 \mathrm{H}$, H-5), $1.91 \sim 1.75$ (m, 5H, H-2, H-3, He-6), $1.58 \sim 1.53(\mathrm{~m}$, $1 \mathrm{H}, \mathrm{Ha}-1), 1.50 \sim 1.46$ (m, 1H, Ha-6), 1.32 (s, 3H, H-19), 1.28 (d, J=6.9 Hz, 6H, H-16, H-17), 1.26 (s, 3H, H-20); ${ }^{13} \mathrm{C} \mathrm{NMR}\left(150 \mathrm{MHz}, \mathrm{CDCl}_{3}\right) \delta: 179.9,148.4,147.1,136.2$, 135.6, 128.4, 125.6, 125.4, 118.6, 65.1, 49.1, 46.2, 39.4, $38.4,38.1,34.9,34.6,31.6,26.7,25.4,23.2$, 20.1, 17.9; IR $(\mathrm{KBr}) v: 2954,2872,1726(\mathrm{C}=\mathrm{O}), 1496,1460,1382$, $1240,1174,1120,1033,979,927,823 \mathrm{~cm}^{-1}$. Anal. calcd for $\mathrm{C}_{24} \mathrm{H}_{33} \mathrm{BrO}_{2}$ : C 66.51, H 7.67; found C 66.55, H 7.65.

12-Bromodehydroabietic acid-2'-bromoethyl ester (4i): White solid, yield $80.0 \%$. m.p. $102.5 \sim 103.8{ }^{\circ} \mathrm{C} ;{ }^{1} \mathrm{H}$ NMR $\left(600 \mathrm{MHz}, \mathrm{CDCl}_{3}\right) \delta: 7.38(\mathrm{~s}, 1 \mathrm{H}, \mathrm{H}-11), 6.93(\mathrm{~s}, 1 \mathrm{H}$, $\mathrm{H}-14), 4.47 \sim 4.32(\mathrm{~m}, 2 \mathrm{H}, \mathrm{H}-21), 3.51$ (t, $J=6.6 \mathrm{~Hz}, 2 \mathrm{H}$, $\mathrm{H}-22), 3.28 \sim 3.25(\mathrm{~m}, 1 \mathrm{H}, \mathrm{H}-15), 2.87 \sim 2.82(\mathrm{~m}, 2 \mathrm{H}$, $\mathrm{H}-7), 2.27 \sim 2.20(\mathrm{~m}, 2 \mathrm{H}, \mathrm{He}-1, \mathrm{H}-5), 1.83 \sim 1.67(\mathrm{~m}, 5 \mathrm{H}$, H-2, H-3, He-6), $1.51 \sim 1.46$ (m, 2H, Ha-1, Ha-6), $1.30(\mathrm{~s}$, $3 \mathrm{H}, \mathrm{H}-19), 1.20 \sim 1.23$ (m, 9H, H-20, H-16, H-17); ${ }^{13} \mathrm{C}$ NMR $\left(150 \mathrm{MHz}, \mathrm{CDCl}_{3}\right) \delta: 179.4,150.2,145.5,135.9$, $129.9,128.6,123.0,65.5,49.1,45.7,39.2,38.4,38.0,33.8$, 31.0, 30.5, 25.6, 24.4, 24.2, 23.0,19.9, 17.9; IR (KBr) v: 2931, 2866, $1718(\mathrm{C}=\mathrm{O}), 1462,1386,1386,1238,1182$, $1105,1033,975,883,804 \mathrm{~cm}^{-1}$. Anal. calcd for $\mathrm{C}_{22} \mathrm{H}_{30^{-}}$ $\mathrm{Br}_{2} \mathrm{O}_{2}$ : C 54.34, H 6.22; found C 54.35, H 6.26. 
12-Bromodehydroabietic acid-3'-bromopropyl ester (4j): White solid, yield $77.0 \%$ m.p. $137.7 \sim 139.7{ }^{\circ} \mathrm{C} ;{ }^{1} \mathrm{H}$ NMR $\left(600 \mathrm{MHz}, \mathrm{CDCl}_{3}\right) \delta: 7.39(\mathrm{~s}, 1 \mathrm{H}, \mathrm{H}-11), 6.94(\mathrm{~s}, 1 \mathrm{H}$, $\mathrm{H}-14), 4.27 \sim 4.20(\mathrm{~m}, 2 \mathrm{H}, \mathrm{H}-21), 3.46(\mathrm{t}, J=6.6 \mathrm{~Hz}, 2 \mathrm{H}$, $\mathrm{H}-23), 3.29 \sim 3.26(\mathrm{~m}, 1 \mathrm{H}, \mathrm{H}-15), 2.89 \sim 2.84(\mathrm{~m}, 2 \mathrm{H}$, H-7), 2.26 (d, $J=12.6 \mathrm{~Hz}, 1 \mathrm{H}, \mathrm{He}-1), 2.17 \sim 2.20(\mathrm{~m}, 3 \mathrm{H}$, $\mathrm{H}-5, \mathrm{H}-22), 1.88 \sim 1.67$ (m, 5H, H-2, H-3, He-6), 1.51 $1.53(\mathrm{~m}, 1 \mathrm{H}, \mathrm{Ha}-1), 1.43 \sim 1.46(\mathrm{~m}, 1 \mathrm{H}, \mathrm{Ha}-6), 1.29(\mathrm{~s}, 3 \mathrm{H}$, $\mathrm{H}-19), 1.22 \sim 1.25$ (m, 9H, H-20, H-16, H-17); ${ }^{13} \mathrm{C}$ NMR $\left(150 \mathrm{MHz}, \mathrm{CDCl}_{3}\right) \delta: 178.2,148.8,144.1,134.3,128.54$, 127.2, 121.5, 62.3, 47.6, 44.6, 37.8 , 37.1, 36.6, 32.3, 31.6, 29.6, 29.5, 25.1, 22.8, 21.6, 18.5, 16.5; IR (KBr) v: 2927, $1712(\mathrm{C}=\mathrm{O}), 1463,1240,1107,1039,979 \mathrm{~cm}^{-1}$. Anal. calcd for $\mathrm{C}_{23} \mathrm{H}_{32} \mathrm{Br}_{2} \mathrm{O}_{2}$ : C 55.22, H 6.45; found $\mathrm{C} 55.24, \mathrm{H}$ 6.41 .

12-Bromodehydroabietic acid-4'-bromobutyl ester (4k): Pale yellow solid, yield 66.8\%. m.p. 95.5 97.9 ${ }^{\circ} \mathrm{C} ;{ }^{1} \mathrm{H}$ NMR (600 MHz, $\left.\mathrm{CDCl}_{3}\right) \delta: 7.39$ (s, 1H, H-11), 6.94 (s, $1 \mathrm{H}, \mathrm{H}-14), 4.16 \sim 4.09$ (m, 2H, H-21), 3.44 (t, $J=6.6 \mathrm{~Hz}$, $2 \mathrm{H}, \mathrm{H}-24), 3.31 \sim 3.26(\mathrm{~m}, 1 \mathrm{H}, \mathrm{H}-15), 2.86 \sim 2.83(\mathrm{~m}, 2 \mathrm{H}$, H-7), 2.26 (d, $J=12.6 \mathrm{~Hz}, 1 \mathrm{H}, \mathrm{He}-1), 2.19$ (d, $J=12.6 \mathrm{~Hz}$, $1 \mathrm{H}, \mathrm{H}-5), 1.95$ (q, $J=6.6 \mathrm{~Hz}, 2 \mathrm{H}, \mathrm{H}-22), 1.81 \sim 1.67$ (m, 7H, H-2, H-3, He-6 and H-23), $1.53 \sim 1.49$ (m, 1H, Ha-1), $1.46 \sim 1.42$ (m, 1H, Ha-6), 1.29 (s, 3H, H-19), 1.25 1.22 (m, 9H, H-20, H-16, H-17); ${ }^{13} \mathrm{C}$ NMR (150 MHz, $\left.\mathrm{CDCl}_{3}\right)$ $\delta: 178.3,148.9,144.1,134.4,128.5,127.2,121.5,63.6$, 47.6, 44.6, 37.9 , 37.0, 36.6, 33.0, 32.3, 29.6, 29.3, 27.4, 25.1, 23.0, 22.8, 21.5, 18.5, 16.5; IR (KBr) v: 2956, 1708 $(\mathrm{C}=\mathrm{O}), 1467,1388,1244,1109,883 \mathrm{~cm}^{-1}$. Anal. calcd for $\mathrm{C}_{24} \mathrm{H}_{34} \mathrm{Br}_{2} \mathrm{O}_{2}$ : C 56.04, H 6.66; found C 56.10, H 6.68.

12-Bromodehydroabietic acid-5'-bromoamyl ester (4I): Pale yellow oil, yield 75.3\%. ${ }^{1} \mathrm{H}$ NMR (600 $\mathrm{MHz}, \mathrm{CDCl}_{3}$ ) $\delta: 7.39$ (s, 1H, H-11), 6.94 (s, 1H, H-14), 4.13 4.07 (m, 2H, H-21), 3.42 (t, $J=6.6 \mathrm{~Hz}, 2 \mathrm{H}, \mathrm{H}-25), 3.28 \sim 3.26(\mathrm{~m}$, $1 \mathrm{H}, \mathrm{H}-15), 2.86 \sim 2.83(\mathrm{~m}, 2 \mathrm{H}, \mathrm{H}-7), 2.26(\mathrm{~d}, J=12.6 \mathrm{~Hz}$, $1 \mathrm{H}, \mathrm{He}-1), 2.20(\mathrm{~d}, J=12.6 \mathrm{~Hz}, 1 \mathrm{H}, \mathrm{H}-5), 1.92 \sim 1.51(\mathrm{~m}$, $11 \mathrm{H}, \mathrm{H}-2, \mathrm{H}-3, \mathrm{He}-6, \mathrm{H}-22, \mathrm{H}-23, \mathrm{H}-24), 1.36 \sim 1.45$ (m, 2H, Ha-1, Ha-6), 1.29 (s, 3H, H-19), 1.22 1.24 (m, 9H, $\mathrm{H}-20, \mathrm{H}-16$ and H-17); ${ }^{13} \mathrm{C}$ NMR $\left(150 \mathrm{MHz}, \mathrm{CDCl}_{3}\right) \delta$ : $178.4,148.9,144.0,134.4,128.5,127.1,121.5,64.3,47.6$, $44.5,37.9,37.0,36.6,33.5,32.3,32.2,29.6,27.9,25.1$, 24.7, 23.0, 21.5, 18.5, 16.4; IR (KBr) v: 2933, $1712(\mathrm{C}=$ O), 1465, 1388, 1246, 1107, $975 \mathrm{~cm}^{-1}$. Anal. calcd for $\mathrm{C}_{25} \mathrm{H}_{36} \mathrm{Br}_{2} \mathrm{O}_{2}$ : C 56.83, H 6.87; found C 56.89, H 6.88.

12,14-Dinitrodehydroabietic acid-2'-bromoethyl ester (4m): Yellow solid, yield 57.1\%. m.p. 158.9 160.6 ${ }^{\circ} \mathrm{C}$; ${ }^{1} \mathrm{H}$ NMR (600 MHz, $\left.\mathrm{CDCl}_{3}\right) \delta: 7.56$ (s, 1H, H-11), 4.49 4.35 (m, 2H, H-21), 3.57 3.54 (m, 2H, H-22), 3.08 3.02 (m, 1H, H-15), $2.90 \sim 2.72$ (m, 2H, H-7), 2.29 (d, $J=12.7$ $\mathrm{Hz}, 1 \mathrm{H}, \mathrm{He}-1), 2.24$ (d, $J=12.7 \mathrm{~Hz}, 1 \mathrm{H}, \mathrm{H}-5), 1.86 \sim 1.69$ (m, 5H, H-2, H-3, He-6), $1.62 \sim 1.54$ (m, 2H, Ha-1, Нa-6), $1.35 \sim 1.32$ (m, 9H, H-16, H-17, H-19), 1.27 (s, 3H, H-20); ${ }^{13} \mathrm{C}$ NMR $\left(150 \mathrm{MHz}, \mathrm{CDCl}_{3}\right) \delta: 177.3,152.1,150.8,149.5$, $130.7,128.5,121.5,64.3,47.4,43.4,37.7,37.6,36.3,29.1$, 29.0, 25.0, 24.6, 20.7, 20.6, 20.2, 18.2, 16.4; IR (KBr) $v$ : 2943, $1722(\mathrm{C}=\mathrm{O}), 1533\left(\mathrm{NO}_{2}\right), 1463,1361,1290,1249$, $1178,1116,790,734 \mathrm{~cm}^{-1}$. Anal. calcd for $\mathrm{C}_{22} \mathrm{H}_{29} \mathrm{BrN}_{2} \mathrm{O}_{6}$ :
C 53.13, H 5.88, N 5.63; found C 53.10, H 5.86, N 5.67.

12,14-Dinitrodehydroabietic acid-3'-bromopropyl ester (4n): Yellow solid, yield 57.7\%. m.p. 131.4 132.6 ${ }^{\circ} \mathrm{C} ;{ }^{1} \mathrm{H}$ NMR $\left(600 \mathrm{MHz}, \mathrm{CDCl}_{3}\right) \delta: 7.56(\mathrm{~s}, 1 \mathrm{H}, \mathrm{H}-11), 4.25 \sim 4.23$ $(\mathrm{t}, J=6.0 \mathrm{~Hz}, 2 \mathrm{H}, \mathrm{H}-21), 3.44 \sim 3.47(\mathrm{t}, J=6.0 \mathrm{~Hz}, 2 \mathrm{H}$, $\mathrm{H}-23), 3.04 \sim 3.02(\mathrm{~m}, 1 \mathrm{H}, \mathrm{H}-15), 2.78 \sim 2.76(\mathrm{~m}, 2 \mathrm{H}$, $\mathrm{H}-7), 2.28$ (d, $J=12.6 \mathrm{~Hz}, 1 \mathrm{H}, \mathrm{He}-1), 2.17 \sim 2.21(\mathrm{~m}, 3 \mathrm{H}$, H-5, H-22), $1.86 \sim 1.73$ (m, 5H, H-2, H-3, He-6), 1.57 1.53 (m, 2H, Нa-1, Нa-6), 1.32 (d, J=7.2 Hz, 6H, H-16, $\mathrm{H}-17), 1.30$ (s, 3H, H-19), 1.26 (s, 3H, H-20); ${ }^{13} \mathrm{C}$ NMR $\left(150 \mathrm{MHz}, \mathrm{CDCl}_{3}\right) \delta: 177.5,150.8,152.2,149.5,130.6$, $128.5,121.4,62.6,47.2$, 43.6, 37.7, 37.6, 36.4, 31.5, 29.2, 29.0, 25.0, 24.6, 20.7, 20.6, 20.2, 18.2, 16.4; IR (KBr) $v$ : 2937, $1718(\mathrm{C}=\mathrm{O}), 1533\left(\mathrm{NO}_{2}\right), 1363,1242,1178,1132$, 983, 902, 779, $732 \mathrm{~cm}^{-1}$. Anal. calcd for $\mathrm{C}_{23} \mathrm{H}_{31} \mathrm{BrN}_{2} \mathrm{O}_{6}: \mathrm{C}$ 54.02, H 6.11, N 5.48; found C 53.96, H 6.15, N 5.47.

12,14-Dinitrodehydroabietic acid-4'-bromobutyl ester (4o): Yellow solid, yield 63.0\%. m.p. 104.3 108.7 ${ }^{\circ} \mathrm{C} ;{ }^{1} \mathrm{H}$ NMR $\left(600 \mathrm{MHz}, \mathrm{CDCl}_{3}\right) \delta: 7.47$ (s, 1H, H-11), 4.05 (t, $J=$ $6.3 \mathrm{~Hz}, 2 \mathrm{H}, \mathrm{H}-21), 3.36(\mathrm{t}, J=6.5 \mathrm{~Hz}, 2 \mathrm{H}, \mathrm{H}-24), 2.99 \sim$ $2.92(\mathrm{~m}, 1 \mathrm{H}, \mathrm{H}-15), 2.75 \sim 2.64(\mathrm{~m}, 2 \mathrm{H}, \mathrm{H}-7), 2.19$ (d, $J=$ $12.6 \mathrm{~Hz}, 1 \mathrm{H}, \mathrm{He}-1), 2.10$ (dd, $J=12.6,2.0 \mathrm{~Hz}, 1 \mathrm{H}, \mathrm{H}-5)$, $1.88 \sim 1.81(\mathrm{~m}, 2 \mathrm{H}, \mathrm{H}-22), 1.78 \sim 1.63(\mathrm{~m}, 7 \mathrm{H}, \mathrm{H}-2, \mathrm{H}-3$, He-6 and H-23), $1.48 \sim 1.41(\mathrm{~m}, 2 \mathrm{H}, \mathrm{Ha}-1$ and Ha-6), 1.25 (d, $J=7.2 \mathrm{~Hz}, 6 \mathrm{H}, \mathrm{H}-17, \mathrm{H}-16), 1.20$ (s, 3H, H-19), 1.17 (s, 3H, H-20); ${ }^{13} \mathrm{C}$ NMR (150 MHz, $\left.\mathrm{CDCl}_{3}\right) \delta: 177.7$, $152.1,150.9,149.5,130.6,128.5,121.5,64.0,47.2,43.5$, $37.7,37.6,36.4,32.9,29.3,29.0,27.3,25.0,24.6,20.7$, 20.6, 20.2, 18.2, 16.5; IR (KBr) v: 2935, 2875, $1716(\mathrm{C}=$ O), $1533\left(\mathrm{NO}_{2}\right), 1462,1365,1244,1180,1120,1024,905$, $823,734 \mathrm{~cm}^{-1}$. Anal. calcd for $\mathrm{C}_{24} \mathrm{H}_{33} \mathrm{BrN}_{2} \mathrm{O}_{6}$ : C 54.86, $\mathrm{H}$ 6.33, N 5.33; found C 54.91, H 6.36, N 5.37.

12,14-Dinitrodehydroabietic acid-5'-bromoamyl ester (4p): Yellow solid, yield 65.7\%. m.p. $111.0 \sim 111.7{ }^{\circ} \mathrm{C}$; ${ }^{1} \mathrm{H}$ NMR $\left(600 \mathrm{MHz}, \mathrm{CDCl}_{3}\right) \delta: 7.56(\mathrm{~s}, 1 \mathrm{H}), 4.11(\mathrm{t}, J=6.4$ $\mathrm{Hz}, 2 \mathrm{H}, \mathrm{H}-21), 3.43$ (t, $J=6.6 \mathrm{~Hz}, 2 \mathrm{H}, \mathrm{H}-25), 3.04$ (dt, $J=$ 14.3, 7.1 Hz, 1H, H-15), 2.77 (dd, $J=9.7,5.4 \mathrm{~Hz}, 2 \mathrm{H}$, H-7), 2.28 (d, $J=13.0 \mathrm{~Hz}, 1 \mathrm{H}, \mathrm{He}-1), 2.20$ (dd, $J=12.6$, $2.1 \mathrm{~Hz}, 1 \mathrm{H}, \mathrm{H}-5), 1.95 \sim 1.49$ (m, 13H, Ha-1, H-2, H-3, H-6, H-22, H-23, H-24), 1.34 (dd, $J=7.1,1.7 \mathrm{~Hz}, 6 \mathrm{H}$, $\mathrm{H}-17, \mathrm{H}-16), 1.29$ (s, 3H, H-19), 1.26 (s, 3H, H-20); ${ }^{13} \mathrm{C}$ NMR $\left(150 \mathrm{MHz}, \mathrm{CDCl}_{3}\right) \delta: 177.7,152.1,150.9,149.5$, $130.6,128.5,121.5,64.6,47.2,43.5,37.7,37.6,36.4,33.4$, $32.2,29.0,27.8,25.0,24.7,24.6,20.7,20.6,20.2,18.2$, 16.4; IR (KBr) v: 2935, $1718(\mathrm{C}=\mathrm{O}), 1533\left(\mathrm{NO}_{2}\right), 1460$, 1365, 1247, 1180, 1130, 1047, 902, 736, 646, $561 \mathrm{~cm}^{-1}$. Anal. calcd for $\mathrm{C}_{25} \mathrm{H}_{35} \mathrm{BrN}_{2} \mathrm{O}_{6}$ : C 55.66, H 6.54, N 5.19; found C 55.70, H 6.56, N 5.15.

12,14-Dinitrodehydroabietic acid-6'-bromohexyl ester (4q): Yellow solid, yield 61.1\%. m.p. 55.5 56.2 ${ }^{\circ} \mathrm{C} ;{ }^{1} \mathrm{H}$ NMR (600 MHz, $\left.\mathrm{CDCl}_{3}\right) \delta: 7.56(\mathrm{~s}, 1 \mathrm{H}, \mathrm{H}-11), 4.13 \sim 4.05$ $(\mathrm{m}, 2 \mathrm{H}, \mathrm{H}-21), 3.42$ (t, $J=6.7 \mathrm{~Hz}, 2 \mathrm{H}, \mathrm{H}-26), 3.04$ (dt, $J=$ 14.3, 7.1 Hz, 1H, H-15), 2.76 (dd, $J=8.9,4.6 \mathrm{~Hz}, 2 \mathrm{H}$, H-7), 2.28 (d, $J=13.0 \mathrm{~Hz}, 1 \mathrm{H}, \mathrm{He}-1), 2.19$ (dd, $J=12.6$, $1.9 \mathrm{~Hz}, 1 \mathrm{H}, \mathrm{H}-5), 1.79 \sim 1.37$ (m, 15H, Ha-1, H-2, H-3, H-6, H-22, H-23, H-24, H-25), 1.34 (dd, $J=7.1,1.6 \mathrm{~Hz}$, 6H, H-17, H-16), 1.29 (s, 3H, H-19), 1.26 (s, 3H, H-20); 
${ }^{13} \mathrm{C}$ NMR $\left(150 \mathrm{MHz}, \mathrm{CDCl}_{3} \mathrm{CDCl}_{3}\right) \delta: 177.7,152.1,150.9$, $149.5,130.6,128.5,121.5,64.8,47.2,43.5,37.7,37.6$, $36.4,33.7,32.5,29.0,28.5,27.7,25.2,25.0,24.7,20.7$, 20.6, 20.2, 18.2, 16.4; IR (KBr) v: 2935, $1720(\mathrm{C}=\mathrm{O})$, $1533\left(\mathrm{NO}_{2}\right), 1462,1365,1246,1180,1130,1047,954$, $902,823,731,648,563 \mathrm{~cm}^{-1}$. Anal. calcd for $\mathrm{C}_{26} \mathrm{H}_{37} \mathrm{Br}-$ $\mathrm{N}_{2} \mathrm{O}_{6}$ : C 56.42, H 6.74, N 5.06; found C 56.46, H 6.76, N 5.10 .

12,14-Dinitrodehydroabietic acid-4'-bromobutenyl ester (4r). Yellow solid, yield 55.1\%. m.p. 113.4 114.1 ${ }^{\circ} \mathrm{C} ;{ }^{1} \mathrm{H}$ NMR (600 MHz, $\left.\mathrm{CDCl}_{3}\right) \delta: 7.56(\mathrm{~s}, 1 \mathrm{H}, \mathrm{H}-11), 5.98(\mathrm{dt}$, $J=15.0,7.4 \mathrm{~Hz}, 1 \mathrm{H}, \mathrm{H}-22), 5.85(\mathrm{t}, J=13.5 \mathrm{~Hz}, 1 \mathrm{H}$, $\mathrm{H}-23), 4.64 \sim 4.57(\mathrm{~m}, 2 \mathrm{H}, \mathrm{H}-21), 3.96(\mathrm{~d}, J=7.4 \mathrm{~Hz}, 2 \mathrm{H}$, H-24), 3.04 (dt, $J=14.3,7.1 \mathrm{~Hz}, 1 \mathrm{H}, \mathrm{H}-15), 2.77$ (dd, $J=$ 10.0, 6.9 Hz, 2H, H-7), 2.28 (d, $J=12.8 \mathrm{~Hz}, 1 \mathrm{H}, \mathrm{He}-1$ ), $2.20(\mathrm{dd}, \quad J=12.6,2.0 \mathrm{~Hz}, 1 \mathrm{H}, \mathrm{H}-5), 1.78(\mathrm{dd}, J=27.9$, $14.1 \mathrm{~Hz}, 5 \mathrm{H}, \mathrm{H}-2, \mathrm{H}-3, \mathrm{He}-6), 1.57 \sim 1.51$ (m, 2H, Ha-1, Ha-6), 1.34 (dd, $J=7.1,1.6 \mathrm{~Hz}, 6 \mathrm{H}, \mathrm{H}-17$ and H-16 ), 1.31 (s, 3H, H-19), 1.26 (s, 3H, H-20); ${ }^{13} \mathrm{C}$ NMR (150 MHz, $\left.\mathrm{CDCl}_{3}\right) \delta: 177.3,152.1,150.9,149.5,130.6,130.4,128.8$, 128.6, 121.5, 63.9, 47.2, 43.5, 37.7, 37.6, 36.3, 31.2, 29.0, 25.0, 24.6, 20.7, 20.6, 20.1, 18.2, 16.4; IR (KBr) v: 2929, $1724(\mathrm{C}=\mathrm{O}), 1533\left(\mathrm{NO}_{2}\right), 1365,1240,1178,1120,960$, $902,732,561 \mathrm{~cm}^{-1}$. Anal. calcd for $\mathrm{C}_{24} \mathrm{H}_{31} \mathrm{BrN}_{2} \mathrm{O}_{6}: \mathrm{C}$ 55.07, H 5.97, N 5.35; found C 55.11, H 6.02, N 5.94.

\subsubsection{Synthetic route for target compounds $\mathbf{5 a} \sim \mathbf{5 r}$}

Under anhydrous conditions, a mixture of the intermediates $4(2.84 \mathrm{mmol})$ in $\mathrm{CH}_{3} \mathrm{CN}(50 \mathrm{~mL})$, coupled with $\mathrm{Ag}$ $\mathrm{NO}_{3}(1.0 \mathrm{~g})$ in the presence of $\mathrm{CH}_{3} \mathrm{CN}(50 \mathrm{~mL})$ was heated with reflux for $5 \mathrm{~h}$ under dark condition. After completion of the reaction, the mixture was filtered and washed with $\mathrm{CH}_{3} \mathrm{CN}$, concentrated with a rotary evaporator and purified by silica gel chromatography with a mixture of petroleum ether and ethyl acetate $(V: V=20: 1)$ as eluent to give the target compounds $\mathbf{5 a} \sim \mathbf{5} \mathbf{r}$.

Dehydroabietic acid-2'-nitrooxyethyl ester (5a): White solid, yield 88.4\%. 52.4 54.4 ${ }^{\circ} \mathrm{C} ;{ }^{1} \mathrm{H}$ NMR $(600 \mathrm{MHz}$, $\left.\mathrm{CDCl}_{3}\right) \delta: 7.17(\mathrm{~d}, J=8.4 \mathrm{~Hz}, 1 \mathrm{H}, \mathrm{H}-11), 7.01(\mathrm{~d}, J=8.4$ $\mathrm{Hz}, 1 \mathrm{H}, \mathrm{H}-12), 6.90$ (s, 1H, H-14), $4.66 \sim 4.65$ (t, $J=4.2$ $\mathrm{Hz}, 2 \mathrm{H}, \mathrm{H}-22), 4.67 \sim 4.30(\mathrm{~m}, 2 \mathrm{H}, \mathrm{H}-21), 2.90 \sim 2.88(\mathrm{~m}$, $2 \mathrm{H}, \mathrm{H}-7), 2.86 \sim 2.81(\mathrm{~m}, 1 \mathrm{H}, \mathrm{H}-15), 2.32(\mathrm{~d}, J=12.6 \mathrm{~Hz}$, $1 \mathrm{H}, \mathrm{He}-1), 2.27 \sim 2.25$ (d, $J=12.6 \mathrm{~Hz}, 1 \mathrm{H}, \mathrm{H}-5), 1.86 \sim$ 1.66 (m, 5H, H-2, H-3 and He-6), $1.53 \sim 1.39$ (m, 2H, Ha-1 and Ha-6), 1.29 (s, 3H, H-19), 1.24 (s, 3H, H-20), 1.22 (d, $J=3.6 \mathrm{~Hz}, 6 \mathrm{H}, \mathrm{H}-16, \mathrm{H}-17) ;{ }^{13} \mathrm{C} \mathrm{NMR}\left(150 \mathrm{MHz}, \mathrm{CDCl}_{3}\right)$ $\delta: 178.4,146.8,145.9,134.7,127.1,124.3,124.1,70.7$, $60.4,47.9,44.9,38.0,37.1,36.6,33.6,30.1,25.3,24.1$, 21.9, 18.6, 16.6; IR (KBr) v: 2927, $1712(\mathrm{C}=\mathrm{O}), 1643$ $\left(\mathrm{ONO}_{2}\right), 1497,1436,1387,1277\left(\mathrm{ONO}_{2}\right), 1246,1174$, 1125, 1052, 896, $843 \mathrm{~cm}^{-1}$; ESI-MS m/z: $412.10[\mathrm{M}+$ $\mathrm{Na}]^{+}$. Anal. calcd for $\mathrm{C}_{22} \mathrm{H}_{31} \mathrm{NO}_{5}$ : C 67.84, H 8.02, N 3.60; found C 67.78, $\mathrm{H}$ 8.06, N 3.61.

Dehydroabietic acid-3'-nitrooxypropyl ester (5b): Colorless liquid, yield 85.2\%. ${ }^{1} \mathrm{H}$ NMR $\left(600 \mathrm{MHz}, \mathrm{CDCl}_{3}\right) \delta$ : 7.20 (d, $J=8.4 \mathrm{~Hz}, 1 \mathrm{H}, \mathrm{H}-11), 7.04$ (d, $J=8.4 \mathrm{~Hz}, 1 \mathrm{H}$, H-12), 6.93 (s, 1H, H-14), 4.55 (t, $J=6.6 \mathrm{~Hz}, 2 \mathrm{H}, \mathrm{H}-23$ ),
$4.24 \sim 4.17(\mathrm{~m}, 2 \mathrm{H}, \mathrm{H}-21), 2.92 \sim 2.89(\mathrm{~m}, 2 \mathrm{H}, \mathrm{H}-7)$, $2.88 \sim 2.84$ (m, 1H, H-15), 2.35 (d, $J=12.6 \mathrm{~Hz}, 1 \mathrm{H}, \mathrm{He}-1)$, $2.26(\mathrm{~d}, J=12.6 \mathrm{~Hz}, 1 \mathrm{H}, \mathrm{H}-5), 2.10(\mathrm{q}, J=6.0 \mathrm{~Hz}, 2 \mathrm{H}$, H-22), $1.90 \sim 1.68$ (m, 5H, H-2, H-3, He-6), $1.44 \sim 1.36$ (m, 2H, Ha-1, Ha-6), 1.31 (s, 3H, H-19), 1.27 (s, 3H, $\mathrm{H}-20), 1.25$ (d, $J=3.6 \mathrm{~Hz}, 6 \mathrm{H}, \mathrm{H}-16, \mathrm{H}-17) ;{ }^{13} \mathrm{C} \mathrm{NMR}$ $\left(150 \mathrm{MHz}, \mathrm{CDCl}_{3}\right) \delta: 178.4,146.9,145.9,134.6,127.1$, $124.3,124.1,70.0,60.6,47.8,44.9,38.0,37.1,36.8,33.6$, 30.2, 25.3, 24.1, 21.9, 18.7 16.6; IR (KBr) v: 2981, 1724 $(\mathrm{C}=\mathrm{O}), 1637\left(\mathrm{ONO}_{2}\right), 1461,1384,1278\left(\mathrm{ONO}_{2}\right), 1102$, 1076, 854, $756 \mathrm{~cm}^{-1}$; ESI-MS m/z: $426.30[\mathrm{M}+\mathrm{Na}]^{+}$. Anal. calcd for $\mathrm{C}_{23} \mathrm{H}_{33} \mathrm{NO}_{5}$ : C 68.46, $\mathrm{H} 8.24, \mathrm{~N} \mathrm{3.47}$; found C 68.44, H 8.21, N 3.49.

Dehydroabietic acid-4'-nitrooxybutyl ester (5c): Colorless liquid, yield 85.0\%. ${ }^{1} \mathrm{H}$ NMR $\left(600 \mathrm{MHz}, \mathrm{CDCl}_{3}\right) \delta$ : $7.17(\mathrm{~d}, J=8.4 \mathrm{~Hz}, 1 \mathrm{H}, \mathrm{H}-11), 7.01(\mathrm{~d}, J=8.4 \mathrm{~Hz}, 1 \mathrm{H}$, $\mathrm{H}-12), 6.90$ (s, 1H, H-14), $4.51 \sim 4.48$ (m, 2H, H-24), $4.13 \sim 4.09(\mathrm{~m}, 2 \mathrm{H}, \mathrm{H}-21), 2.89 \sim 2.87$ (m, 2H, H-7), $2.86 \sim 2.81(\mathrm{~m}, 1 \mathrm{H}, \mathrm{H}-15), 2.30(\mathrm{~d}, J=12.0 \mathrm{~Hz}, 1 \mathrm{H}, \mathrm{He}-1)$, $2.23(\mathrm{~d}, J=12.0 \mathrm{~Hz}, 1 \mathrm{H}, \mathrm{H}-5), 1.89 \sim 1.87$ (m, 2H, H-22), $1.82 \sim 1.63(\mathrm{~m}, 7 \mathrm{H}, \mathrm{H}-2, \mathrm{H}-3, \mathrm{He}-6$ and H-23), $1.52 \sim 1.48$ $(\mathrm{m}, 1 \mathrm{H}, \mathrm{Ha}-1), 1.42 \sim 1.39(\mathrm{~m}, 1 \mathrm{H}, \mathrm{Ha}-6), 1.28(\mathrm{~s}, 3 \mathrm{H}$, H-19), 1.24 (s, 3H, H-16), 1.23 (s, 3H, H-17) ,1.22 (s, 3H, $\mathrm{H}-20) ;{ }^{13} \mathrm{C}$ NMR $\left(150 \mathrm{MHz}, \mathrm{CDCl}_{3}\right) \delta: 178.6,146.9$, $145.9,134.7,127.0,124.3,124.1,72.2,63.7,47.8,44.9$, $38.0,37.1,36.8,33.6,30.0,25.3,25.2,23.5,21.9,18.7$ 16.6; IR (KBr) $v: \mathrm{cm}^{-1}: 2983,1720(\mathrm{C}=\mathrm{O}), 1641\left(\mathrm{ONO}_{2}\right)$, 1446, 1384, $1278\left(\mathrm{ONO}_{2}\right), 1178,1128,1029,984,827$ $\mathrm{cm}^{-1}$; ESI-MS m/z: $417.10[\mathrm{M}]^{+}$. Anal. calcd for $\mathrm{C}_{24} \mathrm{H}_{35^{-}}$ $\mathrm{NO}_{5}$ : C 69.04, H 8.45, N 3.35; found C 69.09, H 8.44, N 3.32 .

Dehydroabietic acid-5'-nitoxypentyl ester (5d): Colorless liquid, yield 78.6\%. ${ }^{1} \mathrm{H}$ NMR $\left(600 \mathrm{MHz}, \mathrm{CDCl}_{3}\right) \delta$ : 7.19 (d, $J=8.4 \mathrm{~Hz}, 1 \mathrm{H}, \mathrm{H}-11), 7.03(\mathrm{~d}, J=8.4 \mathrm{~Hz}, 1 \mathrm{H}$, $\mathrm{H}-12), 6.92$ (s, 1H, H-14), $4.50 \sim 4.46$ (m, 2H, H-25), $4.05 \sim 4.13(\mathrm{~m}, 2 \mathrm{H}, \mathrm{H}-21), 2.91 \sim 2.83(\mathrm{~m}, 3 \mathrm{H}, \mathrm{H}-7$ and H-15), 2.32 (d, $J=12.6 \mathrm{~Hz}, 1 \mathrm{H}, \mathrm{He}-1), 2.26$ (d, $J=12.6$ $\mathrm{Hz}, 1 \mathrm{H}, \mathrm{H}-5), 1.84 \sim 1.48$ (m, 11H, H-2, H-3, He-6, H-22, $\mathrm{H}-23$ and $\mathrm{H}-24), 1.44 \sim 1.34(\mathrm{~m}, 2 \mathrm{H}, \mathrm{Ha}-1$ and Ha-6), 1.29 (s, 3H, H-19), 1.24 1.26 (m, 9H, H-16, H-17 and H-20); ${ }^{13} \mathrm{C}$ NMR $\left(150 \mathrm{MHz}, \mathrm{CDCl}_{3}\right) \delta: 178.6,146.9,145.8$, $134.61,126.9,124.2,124.0,72.7,64.0,47.7,44.8,38.0$, $37.0,36.7,33.5,30.1,25.2,25.0,24.0,21.3,22.2$, 21.7,18.6 16.5; IR (KBr) v: 2937, $1722(\mathrm{C}=\mathrm{O}), 1629$ $\left(\mathrm{ONO}_{2}\right), 1471,1388,1278\left(\mathrm{ONO}_{2}\right), 1244,1176,1009$, 975, 882; ESI-MS m/z: $470.88[\mathrm{M}+\mathrm{K}]^{+} \mathrm{cm}^{-1}$. Anal. calcd for $\mathrm{C}_{25} \mathrm{H}_{37} \mathrm{NO}_{5}$ : $\mathrm{C}$ 69.58, $\mathrm{H} \mathrm{8.64,} \mathrm{N} \mathrm{3.25;} \mathrm{found} \mathrm{C}$ 69.55, H 8.61, N 3.27.

Dehydroabietic acid-6'-nitrohexyl ester (5e): Colorless liquid, yield 84.8\%. ${ }^{1} \mathrm{H}$ NMR $\left(600 \mathrm{MHz}, \mathrm{CDCl}_{3}\right) \delta: 7.14$ (d, $J=8.4 \mathrm{~Hz}, 1 \mathrm{H}, \mathrm{H}-11), 7.01$ (d, $J=8.4 \mathrm{~Hz}, 1 \mathrm{H}, \mathrm{H}-12)$, 6.90 (s, 1H, H-14), $4.50 \sim 4.47$ (m, 2H, H-26), 4.13 4.07 $(\mathrm{m}, 2 \mathrm{H}, \mathrm{H}-21), 2.89 \sim 2.86(\mathrm{~m}, 2 \mathrm{H}, \mathrm{H}-7), 2.86 \sim 2.82(\mathrm{~m}$, $1 \mathrm{H}, \mathrm{H}-15), 2.31$ (d, $J=12.6 \mathrm{~Hz}, 1 \mathrm{H}, \mathrm{He}-1), 2.23$ (d, $J=$ $12.6 \mathrm{~Hz}, 1 \mathrm{H}, \mathrm{H}-5), 1.89 \sim 1.87(\mathrm{~m}, 4 \mathrm{H}, \mathrm{H}-22$ and $\mathrm{H}-25)$, $1.82 \sim 1.64$ (m, 9H, H-2, H-3, He-6, H-23 and H-24), $1.38 \sim 1.52$ (m, 2H, Ha-1 and Ha-6), 1.28 (s, 3H, H-19), 
1.24 (s, 3H, H-20), 1.22 (d, $J=4.8 \mathrm{~Hz}, 6 \mathrm{H}, \mathrm{H}-16$ and $\mathrm{H}-17) ;{ }^{13} \mathrm{C} \mathrm{NMR}\left(150 \mathrm{MHz}, \mathrm{CDCl}_{3}\right) \delta$ : 178.6, 147.0, $145.8,134.7,127.0,124.3,124.0,73.1,64.4,47.7,44.9$, $38.0,37.0,36.7,33.5,30.2,25.7,25.4,25.3,25.2,24.0$, 24.0, 21.8, 18.7 16.5; IR (KBr) v: 2943, $1721(\mathrm{C}=\mathrm{O})$, $1625\left(\mathrm{ONO}_{2}\right), 1460,1383,1280\left(\mathrm{ONO}_{2}\right), 1176,1128$, 1009, 977, 806, $759 \mathrm{~cm}^{-1}$; ESI-MS m/z: $445.88[\mathrm{M}]^{+}$. Anal. calcd for $\mathrm{C}_{26} \mathrm{H}_{39} \mathrm{NO}_{5}$ : C 70.08, $\mathrm{H}$ 8.82, N, 3.14; found $\mathrm{C} 70.10, \mathrm{H} 8.85, \mathrm{~N} 3.11$.

Dehydroabietic acid-8'-nitoxyoctyl ester (5f): Colorless liquid, yield $80.7 \%$. ${ }^{1} \mathrm{H}$ NMR $\left(600 \mathrm{MHz}, \mathrm{CDCl}_{3}\right) \delta: 7.17$ (d, $J=8.4 \mathrm{~Hz}, 1 \mathrm{H}, \mathrm{H}-11), 7.00$ (d, $J=8.4 \mathrm{~Hz}, 1 \mathrm{H}, \mathrm{H}-12)$, 6.89 (s, 1H, H-14), 4.46 4.41 (m, 2H, H-28), $4.10 \sim 4.00$ $(\mathrm{m}, 2 \mathrm{H}, \mathrm{H}-21), 2.88 \sim 2.85(\mathrm{~m}, 2 \mathrm{H}, \mathrm{H}-7), 2.84 \sim 2.80(\mathrm{~m}$, $1 \mathrm{H}, \mathrm{H}-15), 2.25$ (d, $J=12.6 \mathrm{~Hz}, 1 \mathrm{H}, \mathrm{He}-1), 2.25$ (d, $J=$ $12.6 \mathrm{~Hz}, 1 \mathrm{H}, \mathrm{H}-5), 1.82 \sim 1.32(\mathrm{~m}, 17 \mathrm{H}, \mathrm{Ha}-1, \mathrm{H}-2, \mathrm{H}-3$, H-6, H-22, H-23, H-24, H-25, H-26 and H-27), 1.26 (s, $3 \mathrm{H}, \mathrm{H}-19), 1.23$ (s, 3H, H-20), 1.21 (d, $J=4.8 \mathrm{~Hz}, 6 \mathrm{H}$, $\mathrm{H}-16$ and $\mathrm{H}-17) ;{ }^{13} \mathrm{C}$ NMR $\left(150 \mathrm{MHz}, \mathrm{CDCl}_{3}\right) \delta$ : 178.7, $147.0,145.8,134.8,127.0,124.3,124.0,73.4,64.7,47.7$, $44.9,38.1,37.0,36.7,34.1,34.0,32.8,30.2,29.1,29.0$, 28.7, 26.8, 25.9, 25.6, 25.3, 24.1, 24.0, 21.8, 18.7 16.6; IR $(\mathrm{KBr}) v: 2933,2852,1720(\mathrm{C}=\mathrm{O}), 1626\left(\mathrm{ONO}_{2}\right), 1463$, 1382, $1280\left(\mathrm{ONO}_{2}\right), 1246,1176,1126,974,864,758,698$ $\mathrm{cm}^{-1}$; ESI-MS m/z: $474.20[\mathrm{M}+\mathrm{H}]^{+}$. Anal. calcd for $\mathrm{C}_{28} \mathrm{H}_{43} \mathrm{NO}_{5}$ : C 71.00, $\mathrm{H}$ 9.15, N 2.96; found $\mathrm{C} 71.03, \mathrm{H}$ 9.11, N 2.98 .

Dehydroabietic acid-12'-nitrooxydodecyl ester (5g): Colorless liquid, yield 83.5\%. ${ }^{1} \mathrm{H}$ NMR (600 MHz, $\mathrm{CDCl}_{3}$ ) $\delta: 7.21(\mathrm{~d}, J=8.2 \mathrm{~Hz}, 1 \mathrm{H}, \mathrm{H}-11), 7.04$ (d, $J=8.2 \mathrm{~Hz}, 1 \mathrm{H}$, $\mathrm{H}-12), 6.92$ (s, 1H, H-14), 4.47 (t, $J=6.6 \mathrm{~Hz}, 2 \mathrm{H}, \mathrm{H}-32)$, $4.15 \sim 4.02(\mathrm{~m}, 2 \mathrm{H}, \mathrm{H}-21), 2.91 \sim 2.82(\mathrm{~m}, 3 \mathrm{H}, \mathrm{H}-7$ and $\mathrm{H}-15), 2.35 \sim 2.28(\mathrm{~m}, 2 \mathrm{H}, \mathrm{He}-1$ and $\mathrm{H}-5), 1.83 \sim 1.61(\mathrm{~m}$, $10 \mathrm{H}, \mathrm{H}-2, \mathrm{H}-3, \mathrm{He}-6, \mathrm{H}-22, \mathrm{H}-31$ and Ha-1), $1.46 \sim 1.30$ (m, 20H, На-6, H-19, H-23, H-24, H-25, H-26, H-27, H-28, H-29 and H-30), 1.27 (s, 3H, H-20), 1.25 (d, $J=2.4$ $\mathrm{Hz}, 6 \mathrm{H}, \mathrm{H}-16$ and $\mathrm{H}-17)$; ${ }^{13} \mathrm{C} \mathrm{NMR}\left(150 \mathrm{MHz}, \mathrm{CDCl}_{3}\right) \delta$ : $178.7,147.0,145.71,134.7,126.9,124.3,124.0,73.5$, $64.7,47.7,44.8,38.0,37.0,36.6,33.5,30.2,29.5,29.4$, $29.2,29.1,28.7,26.8,26.0,25.7,25.3,24.0,21.8,18.7$, 16.6; IR (KBr) v: 2927, 2856, $1722(\mathrm{C}=\mathrm{O}), 1631\left(\mathrm{ONO}_{2}\right)$, 1462, 1381, $1278\left(\mathrm{ONO}_{2}\right), 1244,1176,1126,1035,947$, $862 \mathrm{~cm}^{-1}$; ESI-MS m/z: $530.01[\mathrm{M}+\mathrm{H}]^{+}$. Anal. calcd for $\mathrm{C}_{32} \mathrm{H}_{51} \mathrm{NO}_{5}$ : C 72.55, $\mathrm{H} 9.70, \mathrm{~N} 2.64$; found $\mathrm{C} 72.53, \mathrm{H}$ 9.72, N 2.61.

Dehydroabietic acid-4'-nitrooxybutene ester (5h): Colorless liquid, yield 88.2\%. ${ }^{1} \mathrm{H}$ NMR $\left(600 \mathrm{MHz}, \mathrm{CDCl}_{3}\right) \delta$ : $7.24(\mathrm{~d}, J=8.4 \mathrm{~Hz}, 1 \mathrm{H}, \mathrm{H}-11), 7.01(\mathrm{~d}, J=8.4 \mathrm{~Hz}, 1 \mathrm{H}$, $\mathrm{H}-12), 6.97$ (s, 1H, H-14), 6.07 $6.04(\mathrm{~m}, 1 \mathrm{H}, \mathrm{H}-23)$, $5.91 \sim 5.86(\mathrm{~m}, 1 \mathrm{H}, \mathrm{H}-22), 4.95(\mathrm{~d}, J=6.6 \mathrm{~Hz}, 2 \mathrm{H}, \mathrm{H}-24)$, $4.71 \sim 4.65(\mathrm{~m}, 2 \mathrm{H}, \mathrm{H}-21), 2.96 \sim 2.94(\mathrm{~m}, 2 \mathrm{H}, \mathrm{H}-7)$, $2.91 \sim 2.88$ (m, 1H, H-15), 2.38 (d, $J=12.0 \mathrm{~Hz}, 1 \mathrm{H}, \mathrm{He}-1)$, $2.33(\mathrm{~d}, J=12.0 \mathrm{~Hz}, 1 \mathrm{H}, \mathrm{H}-5), 1.92 \sim 1.73(\mathrm{~m}, 5 \mathrm{H}, \mathrm{H}-2$, $\mathrm{H}-3$ and He-6), $1.59 \sim 1.47$ (m, 2H, Ha-1 and Ha-6), 1.36 (s, 3H, H-19), 1.30 (s, 3H, H-20), 1.29 (d, J=3.0 Hz, 6H, $\mathrm{H}-16$ and $\mathrm{H}-17) ;{ }^{13} \mathrm{C}$ NMR $\left(150 \mathrm{MHz}, \mathrm{CDCl}_{3}\right) \delta$ : 178.1, $147.0,145.9,134.8,133,0,127.1,124.4,124.2,123.8$,
$72.5,63.6,47.9,45.1,38.2,37.2,36.8,33.7,30.2,25.4$, 24.2, 21.9, 18.8, 16.7; IR (KBr) v: 2956, 2870, $1693(\mathrm{C}=$ O), $1639\left(\mathrm{ONO}_{2}\right), 1458,1382,1274\left(\mathrm{ONO}_{2}\right), 1188,970$, $852 \mathrm{~cm}^{-1}$; ESI-MS m/z: $416.10[\mathrm{M}+\mathrm{H}]^{+}$. Anal. calcd for $\mathrm{C}_{24} \mathrm{H}_{33} \mathrm{NO}_{5}$ : C 69.37, $\mathrm{H}$ 8.00, N 3.37; found $\mathrm{C}$ 69.32, $\mathrm{H}$ 8.02, N 3.33 .

12-Bromodehydroabietic acid-2'-nitrooxyethyl ester (5i): White solid, yield 64.4\%. m.p. $134.1 \sim 136.7{ }^{\circ} \mathrm{C}$; IR (KBr) v: 2927, $1710(\mathrm{C}=\mathrm{O}), 1637\left(\mathrm{ONO}_{2}\right), 1496,1382$, 1244, 1128, 896; ${ }^{1} \mathrm{H}$ NMR (600 MHz, $\left.\mathrm{CDCl}_{3}\right) \delta: 7.37$ (s, 1H, H-11), 6.93 (s, 1H, H-14), 4.53 (t, $J=6$ Hz, 2H, H-22), $4.19(\mathrm{t}, J=6 \mathrm{~Hz}, 2 \mathrm{H}, \mathrm{H}-21), 3.29 \sim 3.25(\mathrm{~m}, 1 \mathrm{H}, \mathrm{H}-15)$, $2.85 \sim 2.80(\mathrm{~m}, 2 \mathrm{H}, \mathrm{H}-7), 2.26(\mathrm{~d}, J=12.0 \mathrm{~Hz}, 1 \mathrm{H}, \mathrm{He}-1)$, $2.17(\mathrm{~d}, J=12.0 \mathrm{~Hz}, 1 \mathrm{H}, \mathrm{H}-5), 2.10 \sim 1.81(\mathrm{~m}, 5 \mathrm{H}, \mathrm{H}-2$, H-3 and He-6), $1.47 \sim 1.51(\mathrm{~m}, 1 \mathrm{H}, \mathrm{Ha}-1), 1.40 \sim 1.43(\mathrm{~m}$, 1H, Ha-6), 1.28 (s, 3H, H-19), 1.23 (s, 3H, H-20), 1.21 (d, $J=6 \mathrm{~Hz}, 6 \mathrm{H}, \mathrm{H}-16$ and $\mathrm{H}-17) ;{ }^{13} \mathrm{C} \mathrm{NMR}(150 \mathrm{MHz}$, $\left.\mathrm{CDCl}_{3}\right) \delta: 179.6,150.2,145.5,135.7,129.9,128.6,123.0$, $71.3,62.0,49.0,46.0,39.2,38.4,38.0,33.8,30.9,26.5$, 24.4, 24.2, 23.0, $19.8 \mathrm{~cm}^{-1}$; ESI-MS m/z: $468.82[\mathrm{M}]^{+}$. Anal. calcd for $\mathrm{C}_{22} \mathrm{H}_{30} \mathrm{BrNO}_{5}$ : C 56.41, H 6.46, N 2.99; found C 56.44, H 6.42, N 3.03.

12-Bromodehydroabietic acid-3'-nitrooxypropyl ester (5j): Pale yellow solid, yield 68.5\%. m.p. 76.4 78.3 ${ }^{\circ} \mathrm{C}$; ${ }^{1} \mathrm{H}$ NMR (600 MHz, $\left.\mathrm{CDCl}_{3}\right) \delta: 7.39$ (s, 1H, H-11), 6.94 (s, $1 \mathrm{H}, \mathrm{H}-14), 4.54$ (t, $J=6.6 \mathrm{~Hz}, 2 \mathrm{H}, \mathrm{H}-23), 4.21 \sim 4.19$ (m, $2 \mathrm{H}, \mathrm{H}-21), 3.31 \sim 3.26(\mathrm{~m}, 1 \mathrm{H}, \mathrm{H}-15), 2.86 \sim 2.82(\mathrm{~m}, 2 \mathrm{H}$, H-7), 2.27 (d, $J=12.6 \mathrm{~Hz}, 1 \mathrm{H}, \mathrm{He}-1), 2.17$ (d, $J=12.6 \mathrm{~Hz}$, $1 \mathrm{H}, \mathrm{H}-5), 2.10 \sim 2.07(\mathrm{~m}, 2 \mathrm{H}, \mathrm{H}-22), 1.87 \sim 1.64(\mathrm{~m}, 5 \mathrm{H}$, H-2, H-3 and He-6), $1.53 \sim 1.49(\mathrm{~m}, 1 \mathrm{H}, \mathrm{Ha}-1), 1.44 \sim 1.41$ (m, 1H, Ha-6), 1.29 (s, 3H, H-19), 1.25 1.22 (m, 9H, $\mathrm{H}-20, \mathrm{H}-16$ and $\mathrm{H}-17) ;{ }^{13} \mathrm{C}$ NMR $\left(150 \mathrm{MHz}, \mathrm{CDCl}_{3}\right) \delta$ : 178.2, 148.8, 144.1, 134.3, 128.5, 127.2, 121.6, 69.9, 60.6, $47.6,44.6,37.8,37.0,36.6,32.3,29.5,26.5,25.1,23.0$, 22.8, 21.6, 18.4, 16.5; IR (KBr) v: 2956, $1722(\mathrm{C}=\mathrm{O})$, $1641\left(\mathrm{ONO}_{2}\right), 1498,1454,1384,1280\left(\mathrm{ONO}_{2}\right), 1174,983$ $\mathrm{cm}^{-1}$; ESI-MS m/z: $504.70[\mathrm{M}+\mathrm{Na}]^{+}$. Anal. calcd for $\mathrm{C}_{23} \mathrm{H}_{32} \mathrm{BrNO}_{5}$ : C 57.26, H 6.69, N 2.90; found $\mathrm{C} 57.22, \mathrm{H}$ $6.70, \mathrm{~N} 2.92$.

12-Bromodehydroabietic acid-4'-nitrooxybutyl ester (5k): White solid, yield 63.6\%. m.p. 101.5 102.8 ${ }^{\circ} \mathrm{C} ;{ }^{1} \mathrm{H}$ NMR (600 MHz, $\left.\mathrm{CDCl}_{3}\right) \delta: 7.39(\mathrm{~s}, 1 \mathrm{H}, \mathrm{H}-11), 6.94(\mathrm{~s}$, $1 \mathrm{H}, \mathrm{H}-14), 4.50(\mathrm{t}, J=6.6 \mathrm{~Hz}, 2 \mathrm{H}, \mathrm{H}-24), 4.15 \sim 4.11(\mathrm{~m}$, $2 \mathrm{H}, \mathrm{H}-21), 3.31 \sim 3.26(\mathrm{~m}, 1 \mathrm{H}, \mathrm{H}-15), 2.86 \sim 2.79(\mathrm{~m}, 2 \mathrm{H}$, H-7), 2.26 (d, $J=12.6 \mathrm{~Hz}, 1 \mathrm{H}, \mathrm{He}-1), 2.18$ (d, $J=12.6 \mathrm{~Hz}$, $1 \mathrm{H}, \mathrm{H}-5), 1.88 \sim 1.67$ (m, 9H, H-2, H-3, He-6, H-22 and H-23), $1.53 \sim 1.49(\mathrm{~m}, 1 \mathrm{H}$, Ha-1), $1.45 \sim 1.42(\mathrm{~m}, 1 \mathrm{H}$, Ha-6), 1.29 (s, 3H, H-19), 1.25 1.22 (m, 9H, H-20, H-16 and $\mathrm{H}-17) ;{ }^{13} \mathrm{C} \mathrm{NMR}\left(150 \mathrm{MHz}, \mathrm{CDCl}_{3}\right) \delta: 178.3,148.9$, $144.1,134.3,128.5,127.2,121.6,72.6,63.7,47.6,44.6$, $37.8,37.0,36.7,32.3,29.6,29.3,27.4,25.1,25.1,23.7$, 23.0, 22.8, 21.6, 18.5, $16.5 \mathrm{~cm}^{-1}$; IR (KBr) v: 2953, 1708 $(\mathrm{C}=\mathrm{O}), 1471,1631\left(\mathrm{ONO}_{2}\right), 1386,1247\left(\mathrm{ONO}_{2}\right), 1024$, 864; ESI-MS $m / z$ : $518.85[\mathrm{M}+\mathrm{Na}]^{+}$. Anal. calcd for $\mathrm{C}_{24} \mathrm{H}_{34} \mathrm{BrNO}_{5}$ : C 58.07, $\mathrm{H}$ 6.90, N 2.82; found $\mathrm{C} 58.11, \mathrm{H}$ $6.87, \mathrm{~N} 2.84$.

12-Bromodehydroabietic acid-5'-nitoxypentyl ester (5l): 
White solid, yield 58.2\%. m.p. 57.1 59.2 ${ }^{\circ} \mathrm{C}$; ${ }^{1} \mathrm{H}$ NMR $\left(600 \mathrm{MHz}, \mathrm{CDCl}_{3}\right) \delta: 7.39$ (s, 1H, H-11), $6.95(\mathrm{~s}, 1 \mathrm{H}$, $\mathrm{H}-14), 4.47$ (t, $J=6.6 \mathrm{~Hz}, 2 \mathrm{H}, \mathrm{H}-25), 4.05 \sim 4.12(\mathrm{~m}, 2 \mathrm{H}$, $\mathrm{H}-21), 3.31 \sim 3.26(\mathrm{~m}, 1 \mathrm{H}, \mathrm{H}-15), 2.87 \sim 2.82(\mathrm{~m}, 2 \mathrm{H}$, $\mathrm{H}-7), 2.26$ (d, $J=12.6 \mathrm{~Hz}, 1 \mathrm{H}, \mathrm{He}-1), 2.19$ (d, $J=12.6 \mathrm{~Hz}$, $1 \mathrm{H}, \mathrm{H}-5), 1.83 \sim 1.68$ (m, 9H, H-2, H-3, He-6, H-22 and $\mathrm{H}-24), 1.51 \sim 1.42$ (m, 4H, Ha-1, Ha-6 and H-23), 1.29 (s, $3 \mathrm{H}, \mathrm{H}-19), 1.22 \sim 1.25$ (m, 9H, H-20, H-16 and H-17); ${ }^{13} \mathrm{C}$ NMR $\left(150 \mathrm{MHz}, \mathrm{CDCl}_{3}\right) \delta: 178.4,148.9,144.1,134.4$, 128.6, 127.2, 121.6, 72.9, 64.1, 47.6, 44.5, 37.9, 37.0, 36.6, $32.3,29.6,28.2,25.1,22.9,22.8,22.4,21.6,18.5,16.5$; IR $(\mathrm{KBr}) v: 2935,1722(\mathrm{C}=\mathrm{O}), 1629\left(\mathrm{ONO}_{2}\right), 1471,1388$, $1278\left(\mathrm{ONO}_{2}\right), 1130,1039,975 \mathrm{~cm}^{-1}$; ESI-MS m/z: 510.83 $[\mathrm{M}]^{+}$. Anal. calcd for $\mathrm{C}_{25} \mathrm{H}_{36} \mathrm{BrNO}_{5}$ : C 58.82, $\mathrm{H} 7.11, \mathrm{~N}$ 2.74; found C 58.81, H 7.13, N 2.74.

12,14-Dinitrodehydroabietic acid-2'-nitrooxyethyl ester (5m): Yellow solid, yield 73.2\%. m.p. $110.5 \sim 111.5{ }^{\circ} \mathrm{C}$; ${ }^{1} \mathrm{H}$ NMR (600 MHz, $\left.\mathrm{CDCl}_{3}\right) \delta: 7.47$ (s, 1H, H-11), 4.24 $4.08(\mathrm{~m}, 2 \mathrm{H}, \mathrm{H}-22), 3.75(\mathrm{t}, J=4.8,2 \mathrm{H}, \mathrm{H}-21), 2.99 \sim$ $2.92(\mathrm{~m}, 1 \mathrm{H}, \mathrm{H}-15), 2.71 \sim 2.67(\mathrm{~m}, 2 \mathrm{H}, \mathrm{H}-7), 2.20(\mathrm{~d}, J=$ $12.0 \mathrm{~Hz}, 1 \mathrm{H}, \mathrm{He}-1), 2.13$ (dd, $J=12.0,2.0 \mathrm{~Hz}, 1 \mathrm{H}, \mathrm{H}-5$ ), $1.80 \sim 1.66(\mathrm{~m}, 5 \mathrm{H}, \mathrm{H}-2, \mathrm{H}-3$ and He-6), $1.52 \sim 1.41(\mathrm{~m}$, 2H, Ha-1 and Ha-6), 1.26 (s, 3H, H-16), 1.24 (s, 3H, $\mathrm{H}-17), 1.22$ (s, 3H, H-19), 1.18 (s, 3H, H-20); ${ }^{13} \mathrm{C}$ NMR $\left(150 \mathrm{MHz}, \mathrm{CDCl}_{3}\right) \delta: 178.3,152.1,150.9,149.5,130.7$, $128.5,121.5,66.4,61.4,47.3,43.6,37.7,37.6,36.3,29.0$, 25.0, 24.7, 20.7, 20.6, 20.2, 18.2, 16.5; IR (KBr) v: 2937, $1726(\mathrm{C}=\mathrm{O}), 1641\left(\mathrm{ONO}_{2}\right), 1533\left(\mathrm{NO}_{2}\right), 1465,1365$, $1288\left(\mathrm{ONO}_{2}\right), 1242,1180,1136,896,848,734,665 \mathrm{~cm}^{-1}$; ESI-MS $m / z: 477.80[\mathrm{M}-\mathrm{H}]^{-}$. Anal. calcd for $\mathrm{C}_{22} \mathrm{H}_{29^{-}}$ $\mathrm{N}_{3} \mathrm{O}_{9}$ : C 55.11, H 6.10, N 8.76; found C 55.08, H 6.13, N 8.73 .

12,14-Dinitrodehydroabietic acid-3'-nitrooxypropyl ester (5n): Yellow solid, yield 76.0\%. m.p. 123.6 $125.2{ }^{\circ} \mathrm{C} ;{ }^{1} \mathrm{H}$ NMR $\left(600 \mathrm{MHz}, \mathrm{CDCl}_{3}\right) \delta: 7.56(\mathrm{~s}, 1 \mathrm{H}$, $\mathrm{H}-11), 4.55(\mathrm{t}, J=6.0 \mathrm{~Hz}, 2 \mathrm{H}, \mathrm{H}-23), 4.25 \sim 4.23(\mathrm{~m}, 2 \mathrm{H}$, $\mathrm{H}-21), 3.07 \sim 3.02(\mathrm{~m}, 1 \mathrm{H}, \mathrm{H}-15), 2.78 \sim 2.76(\mathrm{~m}, 2 \mathrm{H}$, H-7), 2.28 (d, $J=12.6 \mathrm{~Hz}, 1 \mathrm{H}, \mathrm{He}-1), 2.19 \sim 2.17$ (d, $J=$ $12.6 \mathrm{~Hz}, 1 \mathrm{H}, \mathrm{H}-5), 2.08 \sim 2.12(\mathrm{~m}, 2 \mathrm{H}, \mathrm{H}-22), 1.85 \sim 1.74$ $(\mathrm{m}, 5 \mathrm{H}, \mathrm{H}-2, \mathrm{H}-3$ and He-6), $1.51 \sim 1.56$ (m, 2H, Ha- 1 and Ha-6), 1.34 (d, $J=7.2 \mathrm{~Hz}, 6 \mathrm{H}, \mathrm{H}-16$ and H-17), 1.30 (s, $3 \mathrm{H}, \mathrm{H}-19), 1.26$ (s, 3H, H-20); ${ }^{13} \mathrm{C} \mathrm{NMR}(150 \mathrm{MHz}$, $\left.\mathrm{CDCl}_{3}\right) \delta: 177.5,152.1,150.8,149.5,130.5,128.6,121.4$, $69.8,61.0,47.2,43.5,37.7,37.5,36.4,29.0,26.5,25.0$, 24.6, 20.7, 20.6, 20.2, 18.1, 16.4; IR (KBr) v: 2935, 1724 $(\mathrm{C}=\mathrm{O}), 1627\left(\mathrm{ONO}_{2}\right), 1533\left(\mathrm{NO}_{2}\right), 1463,1365,1278$ $\left(\mathrm{ONO}_{2}\right), 1244,1180,1122,1045,983,864 \mathrm{~cm}^{-1}$; ESI-MS $m / z: 491.82[\mathrm{M}-\mathrm{H}]^{-}$. Anal. calcd for $\mathrm{C}_{23} \mathrm{H}_{31} \mathrm{~N}_{3} \mathrm{O}_{9}: \mathrm{C}$ 55.98, H 6.33, N 8.51; found C 55.99, H 6.31, N 8.55.

12,14-Dinitrodehydroabietic acid-4'-nitrooxybutyl ester (5o): Yellow solid, yield 74.2\%. m.p. 105.8 108.3 ${ }^{\circ} \mathrm{C} ;{ }^{1} \mathrm{H}$ NMR $\left(600 \mathrm{MHz}, \mathrm{CDCl}_{3}\right) \delta: 7.56(\mathrm{~s}, 1 \mathrm{H}, \mathrm{H}-11), 4.50(\mathrm{t}, J=$ $6.2 \mathrm{~Hz}, 2 \mathrm{H}, \mathrm{H}-24), 4.17 \sim 4.10(\mathrm{~m}, 2 \mathrm{H}, \mathrm{H}-21), 3.04$ (dt, $J=$ 14.3, 7.1 Hz, 1H, H-15), 2.77 (dd, $J=9.0,4.7 \mathrm{~Hz}, 2 \mathrm{H}$, H-7), 2.28 (d, $J=12.8 \mathrm{~Hz}, 1 \mathrm{H}, \mathrm{He}-1), 2.18$ (dd, $J=12.6$, $2.1 \mathrm{~Hz}, 1 \mathrm{H}, \mathrm{H}-5), 1.87 \sim 1.71$ (m, 9H, H-2, H-3, He-6, $\mathrm{H}-22$ and H-23), 1.53 (t, $J=14.9 \mathrm{~Hz}, 2 \mathrm{H}, \mathrm{Ha}-1$ and Ha-6),
1.34 (dd, $J=7.1,1.8 \mathrm{~Hz}, 6 \mathrm{H}, \mathrm{H}-16$ and H-17), 1.29 (s, 3H, $\mathrm{H}-19), 1.26$ (s, 3H, H-20); ${ }^{13} \mathrm{C} \mathrm{NMR}\left(150 \mathrm{MHz}, \mathrm{CDCl}_{3}\right) \delta$ : 177.6, 152.1, 150.9, 149.5, 130.5, 128.6, 121.4, 72.5, 64.0, $47.2,43.5,37.7,37.6,36.4,29.0,25.1,24.9,24.6,23.7$, 20.7, 20.6, 20.2, 18.2, 16.4; IR (KBr) v: 2929, 2875, 1716 $(\mathrm{C}=\mathrm{O}), 1618\left(\mathrm{ONO}_{2}\right), 1529\left(\mathrm{NO}_{2}\right), 1463,1365,1280$ $\left(\mathrm{ONO}_{2}\right), 1244,1180,981,948,875 \mathrm{~cm}^{-1}$; ESI-MS m/z: $506.87[\mathrm{M}-\mathrm{H}]^{-}$. Anal. calcd for $\mathrm{C}_{24} \mathrm{H}_{33} \mathrm{~N}_{3} \mathrm{O}_{9}$ : C 56.80, $\mathrm{H}$ 6.55, N 8.28; found C 56.83, H 6.56, N 8.29.

12,14-Dinitrodehydroabietic acid-5'-nitoxypentyl ester (5p): Yellow solid, yield 69.9\%. m.p. 44.8 45.2 ${ }^{\circ} \mathrm{C} ;{ }^{1} \mathrm{H}$ NMR $\left(600 \mathrm{MHz}, \mathrm{CDCl}_{3}\right) \delta: 7.56(\mathrm{~s}, 1 \mathrm{H}), 4.49$ (d, $J=6.6$ $\mathrm{Hz}, 2 \mathrm{H}, \mathrm{H}-25), 4.11$ (t, $J=5.7 \mathrm{~Hz}, 2 \mathrm{H}, \mathrm{H}-21), 3.04$ (dt, $J=$ 14.3, 7.1 Hz, 1H, H-15), $2.76(\mathrm{dd}, J=9.2,4.9 \mathrm{~Hz}, 2 \mathrm{H}$, H-7), 2.28 (d, $J=12.8 \mathrm{~Hz}, 1 \mathrm{H}, \mathrm{He}-1$ ), 2.19 (dd, $J=12.6$, $2.0 \mathrm{~Hz}, 1 \mathrm{H}, \mathrm{H}-5), 1.90 \sim 1.45$ (m, 13H, Нa-1, H-2, H-3, $\mathrm{H}-6, \mathrm{H}-22, \mathrm{H}-23$ and H-24), 1.34 (dd, $J=7.1,2.0 \mathrm{~Hz}, 6 \mathrm{H}$, H-16 and H-17), 1.29 (s, 3H, H-19), 1.26 (s, 3H, H-20); ${ }^{13} \mathrm{C} \mathrm{NMR}\left(150 \mathrm{MHz}, \mathrm{CDCl}_{3}\right) \delta: 177.7,152.1,150.9,149.5$, 130.6, 128.5, 121.5, 72.9, 64.4, 47.2 43.6, 37.7, 37.6, 36.4, $29.0,28.2,26.4,24.9,24.7,22.3,20.7,20.6,20.2,18.2$, 16.4; IR (KBr) v: 2943, $1718(\mathrm{C}=\mathrm{O}), 1635\left(\mathrm{ONO}_{2}\right), 1533$ $\left(\mathrm{NO}_{2}\right), 1463,1365,1280\left(\mathrm{ONO}_{2}\right), 1180,1132,1037,979$, 860, 758, 700, 659, $567 \mathrm{~cm}^{-1}$; ESI-MS m/z: $522.74[\mathrm{M}+$ $\mathrm{H}]^{+}$. Anal. calcd for $\mathrm{C}_{25} \mathrm{H}_{35} \mathrm{~N}_{3} \mathrm{O}_{9}$ : C 57.57, H 6.76, N 8.06; found C 57.54, H 6.74, N 8.03.

12,14-Dinitrodehydroabietic acid-6'-nitrohexyl ester (5q): Yellow solid, yield 59\%. m.p. 56.5 57.0 ${ }^{\circ} \mathrm{C} ;{ }^{1} \mathrm{H}$ NMR $\left(600 \mathrm{MHz}, \mathrm{CDCl}_{3}\right) \delta: 7.56(\mathrm{~s}, 1 \mathrm{H}, \mathrm{H}-11), 4.48(\mathrm{~d}$, $J=6.5 \mathrm{~Hz}, 2 \mathrm{H}, \mathrm{H}-26), 4.09(\mathrm{td}, J=10.9,4.3 \mathrm{~Hz}, 2 \mathrm{H}$, H-21), 3.04 (dt, $J=14.3,7.1 \mathrm{~Hz}, 1 \mathrm{H}, \mathrm{H}-15), 2.76$ (dd, 2H, $J=9.0,4.7 \mathrm{~Hz}, \mathrm{H}-7), 2.28$ (d, $J=12.8 \mathrm{~Hz}, 1 \mathrm{H}, \mathrm{He}-1), 2.19$ $(\mathrm{dd}, J=12.6,2.0 \mathrm{~Hz}, 1 \mathrm{H}, \mathrm{H}-5), 1.89 \sim 1.42$ (m, 15H, Ha-1, H-2, H-3, H-6, H-22, H-23, H-24 and H-25), 1.36 1.32 (m, 6H, H-16 and H-17), 1.29 (s, 3H, H-19), 1.26 (s, 3H, $\mathrm{H}-20) ;{ }^{13} \mathrm{C} \mathrm{NMR}\left(150 \mathrm{MHz}, \mathrm{CDCl}_{3}\right) \delta: 177.7,152.1$, $150.9,149.5,130.6,128.5,121.5,73.0,64.7,47.2,43.6$, $37.7,37.6,36.4,29.0,28.4,26.7,26.6,25.7,25.4,25.3$, 25.0, 24.7, 20.7, 20.6, 20.2, 18.2, 16.4; IR (KBr) v: 2943, $1722(\mathrm{C}=\mathrm{O}), 1625\left(\mathrm{ONO}_{2}\right), 1535\left(\mathrm{NO}_{2}\right), 1465,1365$, $1280\left(\mathrm{ONO}_{2}\right), 1182,1134,1045,979,867,759,698,655$, $569 \mathrm{~cm}^{-1}$; ESI-MS m/z: $558.78[\mathrm{M}+\mathrm{Na}]^{+}$. Anal. calcd for $\mathrm{C}_{26} \mathrm{H}_{37} \mathrm{~N}_{3} \mathrm{O}_{9}$ : C 58.31, H 6.96, N 7.85; found $\mathrm{C} 58.33, \mathrm{H}$ 6.94, N 7.82 .

12,14-Dinitrodehydroabietic acid-4'-nitrooxybutene ester (5r): Yellow solid, yield 81.6\%. m.p. 114.9 $115.2{ }^{\circ} \mathrm{C} ;{ }^{1} \mathrm{H}$ NMR $\left(600 \mathrm{MHz}, \mathrm{CDCl}_{3}\right) \delta: 7.56(\mathrm{~s}, 1 \mathrm{H}$, $\mathrm{H}-11), 6.08 \sim 5.95(\mathrm{~m}, 1 \mathrm{H}, \mathrm{H}-23), 5.90 \sim 5.80(\mathrm{~m}, 1 \mathrm{H}$, H-22), 4.94 (d, $J=6.3 \mathrm{~Hz}, 2 \mathrm{H}, \mathrm{H}-24), 4.64$ (d, $J=5.4 \mathrm{~Hz}$, 2H, H-21), 3.04 (dt, J=14.3, 7.1 Hz, 1H, H-15), 2.77 (dd, $J=8.9,4.6 \mathrm{~Hz}, 2 \mathrm{H}, \mathrm{H}-7), 2.29$ (d, $J=13.0 \mathrm{~Hz}, 1 \mathrm{H}, \mathrm{He}-1)$, $2.20(\mathrm{dd}, J=12.6,2.0 \mathrm{~Hz}, 1 \mathrm{H}, \mathrm{H}-5), 1.86 \sim 1.73(\mathrm{~m}, 5 \mathrm{H}$, H-2, H-3 and He-6), $1.57 \sim 1.51(\mathrm{~m}, 2 \mathrm{H}, \mathrm{Ha}-1$ and Ha-6), 1.34 (dd, $J=7.1,1.8 \mathrm{~Hz}, 6 \mathrm{H}, \mathrm{H}-16$ and H-17), 1.31 (s, 3H, $\mathrm{H}-19), 1.26$ (s, 3H, H-20); ${ }^{13} \mathrm{C}$ NMR (150 MHz, $\left.\mathrm{CDCl}_{3}\right) \delta$ : $177.2,152.1,150.8,149.5,132.3,130.6,128.6,128.20$, $124.0,121.5,72.2,63.7,47.3,43.6,37.7,37.6,36.4,29.0$, 
25.0, 24.6, 20.7, 20.6, 20.2, 18.2, 16.4; IR (KBr) v: 2935, $1726(\mathrm{C}=\mathrm{O}), 1631\left(\mathrm{ONO}_{2}\right), 1533\left(\mathrm{NO}_{2}\right), 1465,1365,1276$ $\left(\mathrm{ONO}_{2}\right), 1242,1178,1120,923,852,732,651,567 \mathrm{~cm}^{-1}$; ESI-MS $m / z: 528.10[\mathrm{M}+\mathrm{Na}]^{+}$. Anal. calcd for $\mathrm{C}_{24} \mathrm{H}_{31} \mathrm{~N}_{3} \mathrm{O}_{9}$ : C 57.02, H 6.18, N 8.31; found $\mathrm{C} 57.03, \mathrm{H}$ $6.14, \mathrm{~N} 8.34$.

\subsection{Cytotoxicity testing}

The cytotoxicity assay of the compounds was determined by MTT. Cells were grown in dulbecco's modified eagle medium (DMEM) medium supplemented with 10\% fetal bovine serum (FBS), 1\% penicillin and streptomycin, and grown at $37{ }^{\circ} \mathrm{C}$ in an atmosphere of $5 \% \mathrm{CO}_{2}$ and $95 \%$ air. Cells were routinely trypsinized $(0.05 \%$ tryp$\sin /$ EDTA). All experiments were repeated at least three times. The target compounds were dissolved in dimethyl sulfoxide (DMSO) and added into DMEM. The final DMSO concentration never exceeded $0.1 \%$, and cisplatin was used as the control drug in each experiment.

\subsection{NO release evaluation}

Total NO release amounts in vitro were detected by nitrite/nitrate Assay Kit (Beyotime, China). Firstly, CNE-2 cells $\left(3 \times 100 \mu \mathrm{L}, 5.0 \times 10^{4}\right.$ cells $\left./ \mathrm{mL}\right)$ were incubated in 96 well-plates for $24 \mathrm{~h}$ at $37{ }^{\circ} \mathrm{C}$, and then treated with target compounds ( $4 \mathrm{mmol} / \mathrm{L}$ ) for $24 \mathrm{~h}$. Secondly, the amounts of NO in vitro were measured according to the manufacturer' $s$ instructions. The optical density (OD) value of each well was measured on a microplate reader (BioTek, USA) at $540 \mathrm{~nm}$ and calculated according to the standard curve. Data were mean of three independent experiments.

Supporting Information The ${ }^{1} \mathrm{H}$ NMR and ${ }^{13} \mathrm{C}$ NMR spectra of compounds $\mathbf{4 a} \sim \mathbf{4 r}$ and $\mathbf{5 a} \sim \mathbf{5}$ r. The Supporting Information is available free of charge via the Internet at http://sioc-journal.cn.

\section{References}

[1] Li, Z.-S.; Li, J.-F.; Liu, H.; Shang, S.-B.; Song, Z.-Q. Chem. Ind. Forest. Prod. 2018, 38, 17 (in Chinese).

(李兆双, 李建芳, 刘鹤, 商士斌, 宋湛谦, 林产化学与工业, 2018, 38, 17.)

[2] Rao, X.; Song, Z.; He, L.; Jia, W. Chem. Pharm. Bull. 2008, 56, 1575 .

[3] Huang, X. C.; Jin, L.; Wang, M.; Liang, D.; Chen, Z. F.; Zhang, Y.; Pan, Y. M.; Wang, H. S. Eur. J. Med. Chem. 2015, 89, 370.

[4] Hou, W.; Luo, Z.; Zhang, G.; Cao, D.; Li, D.; Ruan, H.; Ruan, B. H.; Su, L.; Xu, H. Eur. J. Med. Chem. 2017, 138, 1042

[5] Gu, W.; Miao, T. T.; Hua, D. W.; Jin, X. Y.; Tao, X. B.; Huang, C. B.; Wang, S. F. Bioorg. Med. Chem. Lett. 2017, 27, 1296

[6] Huang, X.; Huang, R.; Liao. Z.; Pan, Y.; Gou, S.; Wang, H. Eur. J.
Med. Chem. 2016, 108, 381.

[7] Huang, X. C.; Wang, M.; Pan, Y. M.; Yao, G. Y.; Wang, H. S.; Tian, X. Y.; Qin, J. K.; Zhang, Y. Eur. J. Med. Chem. 2013, 69, 508.

[8] Zhang, W. M.; Yao, Y.; Yang, T.; Wang, X. Y.; Zhu, Z. Y.; Xu, W. T.; Lin, H. X.; Gao, Z. B.; Zhou, H.; Yang, C. G.; Cui, Y. M. Bioorg. Med. Chem. Lett. 2018, 28, 1943.

[9] da Silva, K. R.; Damasceno, J. L.; Inácio, M. O.; Abrão, F.; Ferreira, N. H.; Tavares, D. C.; Ambrosio, S. R. Front Microbiol. 2018, 65,538

[10] Zhou, Z.; Zhou, T. J. Chem. Res. 2018, 42, 405.

[11] Pertino, M. W.; Vega, C.; Rolón, M.; Coronel, C.; Arias, A.R.; Hirschmann, G. S. Molecules 2017, 22, 369

[12] Fonseca, T.; Gigante, B.; Marques, M. M.; Gilchrist, T. L.; De Clercq, E. Bioorg. Med. Chem. 2004, 12, 103 .

[13] Savluchinske-Feio, S.; Nunes, L.; Pereira, P. T.; Silva, A. M.; Roseiro, J. C.; Gigante, B.; Marcelo Curto, M. J. J. Microbiol. Methods 2007, 70, 465 .

[14] Chen, N.; Duan, W.; Lin, G.; Liu, L.; Zhang, R.; Li, D. Mol. Diversity 2016, 20, 897.

[15] Sepúlveda, B.; Astudillo, L.; Rodríguez, J. A.; Yáñez, T.; Theoduloz, C.; Schmeda-Hirschmann, G. Pharmacol. Res. 2005, 52, 429.

[16] Liu, L.; Yan, X. Y.; Gao, Y. Q.; Rao, X. P. Comb. Chem. High Throughput Screen. 2016, 19, 193.

[17] Kang, M. S.; Hirai, S.; Goto, T.; Kuroyanagi, K.; Lee, J. Y.; Uemura, T.; Ezaki, Y.; Takahashi, N.; Kawada, T. Biochem. Biophys. Res. Commun. 2008, 369, 333.

[18] Wada, H.; Kodato, S.; Kawamori, M.; Morikawa, T.; Nakai, H.; Takeda, M.; Saito, S.; Onoda, Y.; Tamaki, H. Chem. Pharm. Bull. 1985, 33, 1472.

[19] Tolmacheva, I. A.; Tarantin, A. V.; Boteva, A. A.; Anikina, L. V.; Tolstikov, A. G. Pharm. Chem. J. 2006, 40, 489.

[20] Mihu, M. R.; Cabral, V.; Pattabhi, R.; Tar, M. T.; Davies, K. P.; Friedman, A. J.; Martinez, L. R.; Nosanchuk, J. D. Antimicrob. Agents. Chemother. 2017, 61, e02020.

[21] Zhao, J.; Gou, S.; Sun, Y.; Yin, R.; Wang, Z. Chemistry 2015, 18, 14276.

[22] Bao, N.; Ou, J. F.; Li, N.; Zou, P.; Sun, J. B.; Chen, L. Eur. J. Med. Chem. 2018, 54, 1.

[23] Naimi, E.; Zhou, A.; Khalili, P.; Wiebe, L. I.; Balzarini, J.; De Clercq, E.; Knaus, E. E. J. Med. Chem. 2003, 46, 995.

[24] Guo, Y.; Wang, Y.; Li, H.; Wang, K.; Wan, Q.; Li, J.; Zhou, Y.; Chen, Y. ACS Med. Chem. Lett. 2018, 9, 502.

[25] Ai, Y.; Kang, F.; Huang, Z.; Xue, X.; Lai, Y.; Peng, S.; Tian, J.; Zhang Y. J. Med. Chem. 2015, 58, 2452.

[26] Xu, S.; Wang, G.; Lin, Y.; Zhang, Y.; Pei, L.; Yao, H.; Hu, M.; Qiu, Y.; Huang, Z.; Zhang, Y.; Xu, J. Bioorg. Med. Chem. Lett. 2016, 26, 2795.

[27] Chen, J.; Wang, T.; Xu, S.; Lin, A.; Yao, H.; Xie, W.; Zhu, Z.; Xu, J. Eur. J. Med. Chem. 2017, 132, 173.

[28] Wang, X.; Pang, F. H.; Huang, L.; Yang, X. P.; Ma, X. L.; Jiang, C. N.; Li, F. Y.; Lei, F. H. Int. J. Mol. Sci. 2018, 19, 3116.

[29] Li, F. Y.; Huang, L.; Li, Q.; Wang, X.; Ma, X. L.; Jiang, C. N.; Duan, W. G.; Lei, F. H. Molecules 2019, 24, 4191.

[30] Li, F. Y.; Wang, X.; Duan, W. G.; Lin, G. S. Molecules 2017, 22, 1087.

[31] Lin, G. S.; Duan, W. G.; Yang, L. X.; Huang, M.; Lei, F. H. Molecules 2017, 22, 193.

[32] Sakuma, T.; Sato, K. US 13/380388, 2012.

[33] Cui, Y. M.; Yasutomi, E.; Otani, Y.; Yoshinaga, T.; Ido, K.; Sawada, K.; Ohwada, T. Bioorg. Med. Chem. Lett. 2008, 18, 5201.

(Lu, Y.) 